\title{
Effect of Wind Speed and Leads on Clear-Sky Cooling over Arctic Sea Ice during Polar Night
}

\author{
DMITRY G. CHECHIN \\ Alfred-Wegener-Institute Helmholtz Centre for Polar and Marine Research, Bremerhaven, Germany, and A.M. Obukhov \\ Institute of Atmospheric Physics, Moscow, Russia \\ IRINA A. MAKHOTINA \\ Arctic and Antarctic Research Institute, St. Petersburg, Russia \\ CHRISTOF LÜPKES \\ Alfred-Wegener-Institute Helmholtz Centre for Polar and Marine Research, Bremerhaven, Germany \\ ALEXANDER P. MAKSHTAS \\ Arctic and Antarctic Research Institute, St. Petersburg, Russia
}

(Manuscript received 10 September 2018, in final form 20 May 2019)

\begin{abstract}
A simple analytical model of the atmospheric boundary layer (ABL) coupled to sea ice is presented. It describes clear-sky cooling over sea ice during polar night in the presence of leads. The model solutions show that the sea ice concentration and wind speed have a strong impact on the thermal regime over sea ice. Leads cause both a warming of the ABL and an increase of stability over sea ice. The model describes a sharp ABL transition from a weakly stable coupled state to a strongly stable decoupled state when wind speed is decreasing. The threshold value of the transition wind speed is a function of sea ice concentration. The decoupled state is characterized by a large air-surface temperature difference over sea ice, which is further increased by leads. In the coupled regime, air and surface temperatures increase almost linearly with wind speed due to warming by leads and also slower cooling of the ABL. The cooling time scale shows a nonmonotonic dependency on wind speed, being lowest for the threshold value of wind speed and increasing for weak and strong winds. Theoretical solutions agree well with results of a more realistic single-column model and with observations performed at the three Russian "North Pole" drifting stations (NP-35, -37, and -39) and at the Surface Heat Budget of the Arctic Ocean ice camp. Both modeling results and observations show a strong implicit dependency of the net longwave radiative flux at the surface on wind speed.
\end{abstract}

\section{Introduction}

The near-surface air temperature is one of the key observed meteorological parameters that reflects thermodynamics of the coupled atmosphere-sea ice system in the Arctic. An identification of physical processes that affect the near-surface temperature is crucial for understanding the observed climate change (Vihma et al. 2014). This is a highly complex task since many interacting mechanisms are involved, but it can be simplified by considering specific thermal regimes over sea ice.

Corresponding author: Dmitry G. Chechin, dmitry.chechin@ awi.de
One such regime is the clear-sky cooling during polar night. It corresponds to one of the typical boundary layer states observed over sea ice in winter (e.g., Stramler et al. 2011), namely, a relatively shallow and stable atmospheric boundary layer (ABL). It is characterized by a negative longwave radiative balance at the sea ice surface resulting in cold temperatures and strong stability. While the longwave radiative heat loss from the surface is the main driver of cooling, other factors also influence this thermal regime. Two such factors are the main topic of this study. The first is wind speed, which is responsible for the turbulent coupling between the ABL and the surface, and the second is the occurrence of leads, which represents a source of heat for the ABL. 
Previous studies demonstrated that wind speed has a strong effect on air temperature and the temperature difference $\Delta \theta=\theta_{a}-\theta_{s}$, where $\theta_{a}$ and $\theta_{s}$ are the nearsurface air and surface potential temperatures. Walsh and Chapman (1998), Vihma and Pirazzini (2005), and Lüpkes et al. (2008b) showed that higher wind speed over sea ice is associated with warmer air temperature. Vihma and Pirazzini (2005) suggested that this might be due to increased entrainment of warmer air from above the ABL. Lüpkes et al. (2008b) also pointed out that it takes longer to cool a thicker ABL that develops during stronger winds.

Low wind speed is associated with increased values of $\Delta \theta$ as observed in the stable surface layer in the Antarctic (Cassano et al. 2016; Vignon et al. 2017), while higher wind leads to stronger coupling between the air and the surface and thus to reduced values of $\Delta \theta$. This was also found in the results of idealized modeling of the ABL processes over the Arctic sea ice (Lüpkes et al. 2008b; Sterk et al. 2013) and snow-covered land surface (Savijärvi 2014). The governing role of wind speed for the transition from the weakly stable regime to the strongly stable one was highlighted by Van de Wiel et al. (2017), who presented a conceptual analytical model of the stable ABL.

Another factor influencing $\theta_{a}$ and $\Delta \theta$ is the presence of leads, which were shown (Lüpkes et al. 2008b; Tetzlaff et al. 2013) to strongly warm the ABL. In addition, Lüpkes et al. (2008b) showed using a numerical 1D model that leads increase the stability over the ice floes. An important role in this process plays the formation of internal boundary layers over leads and adjacent ice (e.g., Lüpkes et al. 2008a; Tetzlaff et al. 2015). Leads can also serve as sources of moisture (Andreas et al. 2002) that might result in condensation and, consequently, impact the radiative balance (e.g., Pinto and Curry 1995).

The goal of this study is to further investigate the sensitivity of $\theta_{a}, \theta_{s}$, and $\Delta \theta$ to the wind speed and sea ice concentration (SIC). To that aim, an analytical model is proposed describing the thermal state of the coupled ABL-snow-sea ice system. Conceptually, the model is similar to the one presented earlier by Van de Wiel et al. (2017). Their model is a coupled soil-ABL model describing the regime transition from a weakly to a strongly stable state. Essential for their model is the dependency of the bulk turbulent heat transfer coefficient in the ABL on stability. In this aspect, our model is similar to the one of Van de Wiel et al. (2012) and Van de Wiel et al. (2017), but there are several differences: 1 ) the ABL bulk temperature is not fixed but is allowed to depend on wind speed, SIC, and other parameters; 2) the parameters of the model, such as the heat conductivity and thickness of the ice and snow layers, the atmospheric effective emissivity, are not combined into a single so-called "lumped" parameter and their values are set to the typically observed ones in the central Arctic; 3 ) the timedependent solution takes into account the dependency of the ABL height on wind speed, which is not considered in the Van de Wiel et al. model; and 4) the heat flux from leads is taken into account. Therefore, our model can be seen as a further development of the Van de Wiel et al. model toward more realism in representing Arctic conditions.

Both steady-state and time-dependent solutions are presented and discussed. We also use a less idealized numerical 1D model, which consists of an atmospheric single-column model coupled to a simple sea ice and snow model. This model is used to verify some of the assumptions used in the analytical model.

Results of both analytical and numerical models are compared with the observations from the three Russian "North Pole" drifting stations: NP-35 (2007-08), NP-37 (2009-10), and NP-39 (2011-12) and also with the data from the Surface Heat Budget of the Arctic Ocean (SHEBA) campaign (Persson et al. 2002). The recent NP data are described in Makshtas et al. $(2014,2019)$ and Makhotina et al. (2019) and will be soon open for free access at the website of the Arctic and Antarctic Research Institute, St. Petersburg, Russia (http:// www.aari.ru/). The drift trajectories of the stations were located in different parts of the Arctic Ocean. Thus, the observations represent a broad range of synoptic and sea ice conditions. The observations are used to document the sensitivity of $\theta_{a}, \Delta \theta$, and the net longwave radiative flux at the surface to wind speed, but not to SIC. The reason is that the latter was not directly observed at the NP stations. A detailed analysis of SIC in the area around the NP stations should involve satellite data and is left for future research.

The structure of the paper is as follows. First, a simple analytical model is presented and its steady-state solution is derived (section 2). A numerical 1D model is presented in section 3. Observations at the NP stations are described in section 4. In section 5, the steady-state solution is analyzed and compared to the results of the 1D model. The results of both analytical and numerical models are compared to observations in section 6. Main results are summarized in section 7 .

\section{Steady-state analytical model}

We consider the temperature evolution in a coupled system consisting of a bulk ABL and two surface types: 1) a sea ice slab covered with snow and 2) open leads. Temperature in the ABL and in the ice and snow layers 


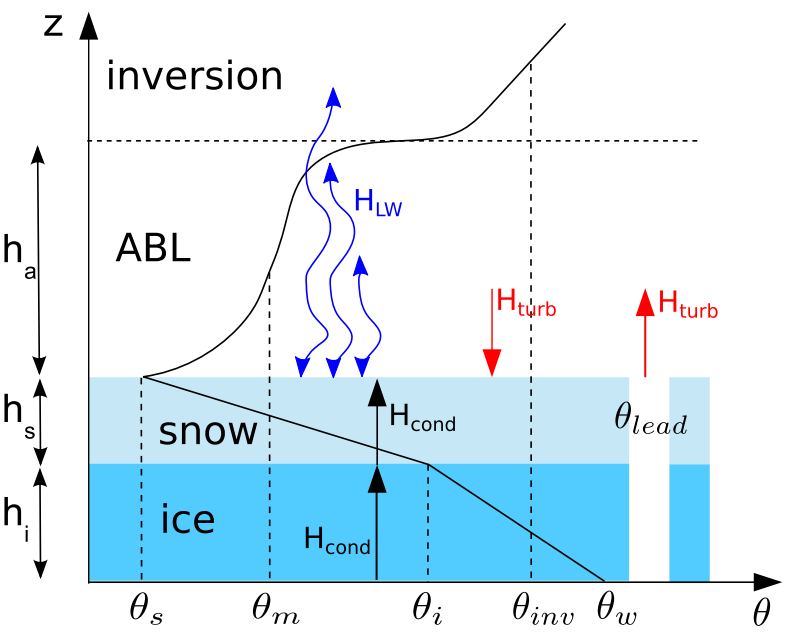

FIG. 1. Schematic representation of the temperature profile and fluxes in a three-layer coupled model of the ABL, snow, and sea ice. Red arrows show turbulent fluxes $H_{\text {turb }}$, blue arrows show longwave radiative fluxes $H_{\mathrm{LW}}$, and black arrows show conductive fluxes $H_{\text {cond }}$.

is representative of a large region (e.g., $100 \mathrm{~km} \times$ $100 \mathrm{~km}$ ) in the central Arctic in which multiple leads are present.

An idealized vertical profile of temperature in the considered coupled system is shown in Fig. 1. The ambient inversion layer above the ABL is assumed to have constant temperature fixed to some typical value. As shown further, the inversion temperature in our model is only influencing the downwelling longwave radiative flux. The temperature at the lower boundary of the sea ice slab is set to the freezing point of salty seawater: $\theta_{w}=$ $271.35 \mathrm{~K}$. It serves as a boundary condition to obtain the conductive flux through the ice layer. The lead surface temperature $\theta_{\text {lead }}$ is also set to the freezing point. The ABL temperature $\theta_{m}$ (and the near-surface air temperature $\theta_{a}$ ), snow surface temperature $\theta_{s}$, and temperature at the ice-snow interface $\theta_{i}$ are functions of time and model parameters/forcings. Here, we focus on the effect of wind speed and sea ice concentration.

The ABL and the snow-ice layer are interacting with each other by means of radiative, conductive, and turbulent fluxes of heat. The turbulent heat flux at the lower ABL boundary is the area-weighted flux consisting of fluxes over leads and ice floes, which are aggregated using the so-called tile or mosaic approach.

First, we consider the steady-state limit. Steady state is assumed in all three layers. Thus, in the ABL, in the absence of entrainment at its top, a positive turbulent heat flux from leads is balanced by a negative heat flux over sea ice and by longwave radiative cooling. Temperature profiles in the snow and ice layers are linear and the conductive heat flux in the ice layer is equal to the one in the snow layer. At the snow surface a balance between radiative, conductive, and turbulent fluxes is assumed.

As a result, the following system of the steady-state equations can be written:

$$
\begin{gathered}
0=A C_{H, s} U\left(\theta_{s}-\theta_{a}\right)+(1-A) C_{H, w} U\left(\theta_{\text {lead }}-\theta_{a}\right)+R_{\text {cool }}, \\
0=-\frac{k_{i}}{h_{i}}\left(\theta_{i}-\theta_{w}\right)+\frac{k_{s}}{h_{s}}\left(\theta_{s}-\theta_{i}\right), \\
\mathrm{LW}+\frac{k_{s}}{h_{s}}\left(\theta_{i}-\theta_{s}\right)=\rho_{a} c_{p} C_{H, s} U\left(\theta_{s}-\theta_{a}\right)
\end{gathered}
$$

where $\theta_{a}$ is the potential temperature at some height in the surface layer; $\theta_{s}$ is the snow surface temperature; $\theta_{i}$ is the ice-snow interface temperature; $U$ is wind speed at some height in the surface layer; $A$ is the sea ice concentration; $C_{H, s}$ and $C_{H, w}$ are the transfer coefficients for heat over sea ice and leads, respectively; $R_{\text {cool }}$ is the difference of the net longwave radiative flux at the bottom and at the top of the ABL representing the longwave cooling of the ABL; $k_{i, s}$ and $h_{i, s}$ are the thermal conductivities and thickness of ice and snow layers, respectively; and LW is the net longwave radiative flux at the surface. We use for potential temperature $\theta_{a}=T_{a}\left(p_{0} / p\right)^{\gamma}$, where $\gamma=R / c_{p}$ and $p_{0}=1000 \mathrm{hPa}$. Thereby, we assume $p=p_{0}$ so that $\theta_{s}=T_{s}$ at the surface.

The first two equations [(1) and (2)] are the steadystate heat conservation equations in the $\mathrm{ABL}$ and in the snow-ice layer. Note that, for simplicity, it is assumed that the ABL height $h_{a}$ and wind speed $U$ are the same over the ice and leads and, thus, $h_{a}$ is cancelled out from (1) in the steady-state limit. In reality, $U$ can be different over leads and the adjacent ice due to formation of the internal boundary layers and contrasting stability (e.g., Tetzlaff et al. 2013). We anticipate that in the nonstationary case, $h_{a}$ and $U$ are still present in the equation for $\theta_{a}$ and influence the cooling time scale (see appendix B). Equation (3) is the heat balance equation at the snow surface.

In the following, the constant values of 0.21 and $2.2 \mathrm{~W} \mathrm{~m}^{-1} \mathrm{~K}^{-1}$ are used for $k_{s}$ and $k_{i}$ and 0.3 and $2 \mathrm{~m}$ for $h_{s}$ and $h_{i}$, respectively. These values are typical in the central Arctic during winter (e.g., Overland and Guest 1991; Lüpkes et al. 2008b). In nature, the variability of thermodynamic properties of snow and sea ice is large (e.g., Makshtas 1998), as they depend on many factors. Especially $\theta_{a}$ and $\theta_{s}$ are sensitive to $k_{s, i}$ and $h_{s, i}$, and the analytical model describes this sensitivity (see appen$\operatorname{dix}$ A). Nevertheless, the main conclusions of this study are valid for a large range of values of these parameters. 
We assume for simplicity that the exchange coefficient for heat over leads $C_{H, w}$ is constant and independent of stability, whereas in reality $C_{H, w}$ is directly influenced by convective heat transport. For the exchange coefficient for heat over sea ice $C_{H, s}$ we use two alternatives. The first option is to assume that $C_{H, s}$ is equal to its value for neutral stratification $C_{H n}$, namely,

$$
C_{H, s}=C_{H n}=\frac{\kappa^{2}}{\ln \left(z / z_{0 m}\right) \ln \left(z / z_{0 t}\right)},
$$

where $\kappa$ is the von Kármán constant equal to $0.4 ; z_{0 m}$ and $z_{0 t}$ are the roughness lengths for momentum and heat, respectively; and $z$ is some height in the surface layer. For momentum we use $z_{0 m}=1 \times 10^{-3} \mathrm{~m}$ over sea ice and $z_{0 m}=1 \times 10^{-4} \mathrm{~m}$ over leads. For the scalar roughness length we use $z_{0 t}=0.1 z_{0 \mathrm{~m}}$ both over ice and leads. In the following, we use $z=4 \mathrm{~m}$, which results in $C_{H n}$ equal to $1.82 \times 10^{-3}$ over sea ice and $1.17 \times 10^{-3}$ over leads. The latter corresponds to the value $1 \times 10^{-3}$ for $C_{H n}$ at $10 \mathrm{~m}$, which is typical for leads (Andreas and Cash 1999).

Although the prescribed values of $z_{0 m}$ and $z_{0 t}$ are typical over sea ice, they have a large scatter in nature spanning over several orders of magnitude (Andreas et al. 2010; Gryanik and Lüpkes 2018). The sensitivity of the results to the values of $z_{0 m}$ and $z_{0 t}$ is discussed in section 6 and in appendix A.

The second option is to account for the stability dependence of $C_{H, s}$. To that aim, a Louis-type (Louis et al. 1982) stability correction is used, namely,

$$
C_{H, s}=C_{H n}\left(1+\alpha \mathrm{Ri}_{b}\right)^{-1},
$$

where $\alpha$ is a constant. Bulk Richardson number $\mathrm{Ri}_{b}$ is defined as

$$
\mathrm{Ri}_{b}=\frac{z g\left(\theta_{a}-\theta_{s}\right)}{\Theta_{0} U^{2}},
$$

where $\Theta_{0}=250 \mathrm{~K}$ is a constant representative potential temperature. We use $\alpha=20$ (instead of $\alpha=15$ proposed by Louis), which results in a rather good agreement between theoretical and the 1D model results.

Note that the steady-state model can be solved numerically by iterations for any stability function expressed in terms of either $\mathrm{Ri}_{b}$ or $z / L$, where $L$ is the Obukhov length. In this study, we choose the Louis function as it allows us to obtain a simple analytical solution. However, one should keep in mind that the longtail functions, such as the Louis ones, produce too much mixing compared to local observations. They were introduced to improve the performance of the coarse-grid models. A good example is the study by Savijärvi (2009), where it is shown that the unresolved mixing due to the mesoscale terrain effects can be taken into account by using the long-tail stability functions. However, shorttail forms (e.g., Businger-Dyer functions) are more consistent with turbulence theory. Moreover, the icecovered Arctic ocean represents a rather homogeneous surface over which the extra mixing might not be required (e.g., Gryanik and Lüpkes 2018). Thus, while we prefer the Louis functions for their simplicity, below we briefly discuss the sensitivity of our model results to the choice of stability functions.

Earlier studies, such as McNider et al. (2012) and Van de Wiel et al. (2017), demonstrated the sensitivity of the wind speed of transition between the two stability regimes to the used stability functions. Namely, the longtail functions result in smaller values of the transition wind speed. Also, the above studies show that some stability functions, especially the short-tail and the cutoff ones, result in the existence of multiple solutions for $\theta_{a}$ and $\Delta \theta$ in a certain range of wind speed. Although we use a different analytical model, we obtained the same results in the sensitivity experiments (not show here) using different stability functions and also varying the value of $\alpha$ in (5). In particular, larger values of $\alpha$ (shorter tail) result in larger values of the transition wind speed.

The height in the surface layer $z$ is an important model parameter, as the effect of stability on $C_{H, s}$ is increasing with increasing $z$. A physically motivated choice of $z$ is not trivial. Over the inhomogeneous surface $z$ has to be above the blending height, but low enough to be still in the surface layer. As shown by Tetzlaff et al. (2015), the internal convective boundary layer over leads can reach the capping inversion which is typically placed at about 100-200-m height in winter. In this case, the blending height might not exist at all. This represents a drawback of the mosaic flux-aggregation method, which is used here and in many coarse-resolution models. Our choice of $z=4 \mathrm{~m}$ is motivated by the proximity to the observational levels at the NP stations, which are at 2- and 8-m heights for temperature and $10 \mathrm{~m}$ for wind. At the same time the level $z$ must not be too low so that the effects of stability are still taken into account.

The net longwave flux at the surface is

$$
\mathrm{LW}=R_{\text {down }}+R_{\text {up }}
$$

For the outgoing longwave radiative flux $R_{\text {up }}$ the StefanBoltzmann law for a gray body is used, namely,

$$
R_{\text {up }}=-\varepsilon_{s} \sigma \theta_{s}^{4},
$$

where $\varepsilon_{s}=0.98$ is the emissivity of snow and $\sigma=5.67 \times$ $10^{-8} \mathrm{~W} \mathrm{~m}^{-2} \mathrm{~K}^{-4}$ is the Stefan-Boltzmann constant. 
For the downwelling longwave flux $R_{\text {down }}$ a modified parameterization of König-Langlo and Augstein (1994) (KLA) is used. The original KLA parameterization is given by $R_{\text {down }}=\varepsilon_{s} \sigma \varepsilon_{a} \theta_{a}^{4}$, where $\varepsilon_{a}$ is the effective atmospheric emissivity. In the KLA parameterization the near-surface air temperature $\theta_{a}$ is used. Instead, we use an average between $\theta_{a}$ and the typical inversion temperature above the ABL $\theta_{\text {inv }}$. The basis for this is that the downwelling radiation is formed not only in the surface layer but also in a thicker lower bulk of the atmosphere. As a consequence, in clear-sky situations with strong inversions the values of observed LW are less negative compared to the situations with weak inversions (Niemelä et al. 2001; Stramler et al. 2011; Pithan et al. 2016). The proposed modification is very simple. Although it does not account for the actual temperature profile in the ABL and capping inversion, it captures, to some extent, the described dependency. Thus, for $R_{\text {down }}$ we use

$$
R_{\mathrm{down}}=\varepsilon_{s} \sigma \varepsilon_{a}\left(\frac{\theta_{a}+\theta_{\mathrm{inv}}}{2}\right)^{4}
$$

where $\varepsilon_{a}=0.765$ is the empirical atmospheric emissivity in clear sky conditions obtained by König-Langlo and Augstein (1994) using the observations at the Neumayer station in the Antarctic and at the Koldewey station in Ny-Ålesund (Svalbard). For $\theta_{\text {inv }}$ the constant value $242 \mathrm{~K}$ is used. For some applications, $\theta_{\text {inv }}$ can be interpreted as the radiative-advective equilibrium temperature (e.g., Overland and Guest 1991). Longwave radiation depends on absolute temperature, but for simplicity, in (9) it is assumed that $T_{a} \approx \theta_{a}$.

The net longwave flux LW is linearized around $\theta_{\text {inv }}$ using a Taylor series expansion. This results in

$$
\mathrm{LW}=\mathrm{LW}_{i}-\lambda_{\mathrm{Ri}}\left(\theta_{s}-\theta_{\text {inv }}\right)-\lambda_{\mathrm{Ra}}\left(\theta_{s}-\theta_{a}\right),
$$

where $\mathrm{LW}_{i}$ is the so-called isothermal net longwave radiative flux (van Ulden and Holtslag 1985) given by

$$
\mathrm{LW}_{i}=-\varepsilon_{s} \sigma\left(1-\varepsilon_{a}\right) \theta_{\mathrm{inv}}^{4} .
$$

For $\theta_{\text {inv }}=242 \mathrm{~K}, \mathrm{LW}_{i}$ amounts to about $-45 \mathrm{~W} \mathrm{~m}^{-2}$. The thermal conductances $\lambda_{\mathrm{Ri}}$ and $\lambda_{\mathrm{Ra}}$ represent efficiencies of the radiative heat exchange between the inversion and surface (index $i$ ) and the ABL and surface (index $a$ ), respectively, and are given by

$$
\begin{aligned}
& \lambda_{\mathrm{Ri}}=2 \varepsilon_{s}\left(2-\varepsilon_{a}\right) \sigma \theta_{\mathrm{inv}}^{3}, \\
& \lambda_{\mathrm{Ra}}=2 \varepsilon_{s} \varepsilon_{a} \sigma \theta_{\mathrm{inv}}^{3} .
\end{aligned}
$$

The last term, which needs to be parameterized in the steady-state model, is the divergence of the radiative fluxes in the ABL $R_{\text {cool }}$ (longwave cooling). At low wind speed, when stability over sea ice is strong enough to diminish the turbulent heat flux, it is $R_{\text {cool }}$ that effectively balances the heating of the ABL by leads. Therefore, we assume that $R_{\text {cool }}$ is a function of stability over ice and that it is also proportional to $\theta_{s}-\theta_{a}$. The latter means nudging of $\theta_{a}$ to $\theta_{s}$. Thus, we parameterize $R_{\text {cool }}$ as

$$
R_{\text {cool }}=\lambda^{\prime} \frac{\mathrm{Ri}_{b}}{1+\alpha \mathrm{Ri}_{b}}\left(\theta_{s}-\theta_{a}\right)
$$

where $\alpha$ is the same as in (5) and $\lambda^{\prime}=1.6 \times 10^{-4} \mathrm{~s}^{-1}$ is the constant, which value is chosen to balance the heating from leads and result in $\theta_{a}$ and $\Delta \theta$ values close to the single-column model results. Therefore, $\lambda^{\prime}$ is used here rather as a tuning parameter and its value is not based on observations. Note, that $R_{\text {cool }}$ is only important at low wind speed in the range of about $0-2 \mathrm{~m} \mathrm{~s}^{-1}$. Qualitatively, the inclusion of the term $R_{\text {cool }}$ does not change the main results of the study, thus we do not discuss here in detail the proposed parameterization or alternatives to it.

Before deriving the steady-state solution it is worth to note that with our assumptions all fluxes in the system (1)-(3) apart from $\mathrm{LW}_{i}$, which is constant, are brought to a form $\lambda \Delta \theta$, where $\lambda$ is a so-called thermal conductance and $\Delta \theta$ is a temperature difference between two components of the system.

To obtain the steady-state solution it is useful to introduce first the surface temperature $\theta_{\text {rad }}$ that would result from the radiative-conductive equilibrium in the absence of turbulent heat flux. To that aim, we use (2) and (10) in (3) and assume $\theta_{a}=\theta_{s}=\theta_{\text {rad }}$, which results in

$$
\mathrm{LW}_{i}-\lambda_{\mathrm{Ri}}\left(\theta_{\text {rad }}-\theta_{\text {inv }}\right)+\lambda_{C}\left(\theta_{w}-\theta_{\text {rad }}\right)=0,
$$

where the effective thermal conductance of the icesnow slab $\lambda_{C}$ is given by

$$
\lambda_{C}=\left(\frac{k_{s}}{h_{s}}\right)\left(\frac{k_{i} h_{s}}{k_{i} h_{s}+k_{s} h_{i}}\right) .
$$

From (15) we obtain

$$
\theta_{\mathrm{rad}}=\frac{\mathrm{LW}_{i}+\lambda_{\mathrm{Ri}} \theta_{\mathrm{inv}}+\lambda_{C} \theta_{w}}{\lambda_{C}+\lambda_{\mathrm{Ri}}} .
$$

Let us consider the new variable, which is the normalized temperature difference $\overline{\Delta \theta}=\left(\theta_{a}-\theta_{s}\right) /\left(\theta_{\text {lead }}-\theta_{\text {rad }}\right)$.

In case of constant $C_{H, s}=C_{H n}$ we can neglect $R_{\text {cool }}$ according to (14). In this case, the system (1)-(3) is linear with respect to $\overline{\Delta \theta}$ and its solution is 


$$
\overline{\Delta \theta_{c}}=\left[\frac{\rho_{a} c_{p} C_{H n} U+\lambda_{\mathrm{Ra}}}{\lambda_{C}+\lambda_{\mathrm{Ri}}}+\frac{A C_{H n}}{(1-A) C_{H, w}}+1\right]^{-1},
$$

where index $c$ in $\Delta \theta_{c}$ designates that this is the solution for constant $C_{H n}$. Note, that for the second term on the right-hand side of (18) we can write

$$
\frac{A C_{H n}}{(1-A) C_{H, w}}=\frac{A \lambda_{T s}}{(1-A) \lambda_{T l}},
$$

where $\lambda_{T s}=\rho_{a} c_{p} C_{H, s} U$ and $\lambda_{T l}=\rho_{a} c_{p} C_{H, w} U$ are the thermal conductances characterizing turbulent heat transfer over sea ice and leads, respectively. Thus, (18) shows that $\overline{\Delta \theta_{c}}$ depends only upon the nondimensional ratios of thermal conductances of various parts of the system and upon the sea ice concentration $A$.

For the stability-dependent $C_{H, s}$ given by (5) the system (1)-(3) results in a quadratic equation with respect to $\overline{\Delta \theta}$, namely,

$$
\mathscr{b} \overline{\Delta \theta}^{2}+\mathscr{B} \overline{\Delta \theta}+\mathscr{C}=0,
$$

where

$$
\begin{aligned}
& \mathscr{C}=\alpha \widehat{\mathrm{Ri}}_{b}\left[\frac{\lambda_{\mathrm{Ra}}}{\lambda_{\mathrm{Ri}}+\lambda_{C}}+\frac{\lambda^{\prime} / U}{(1-A) C_{H, w}}+1\right], \\
& \mathscr{B}=\Delta \theta_{c}^{-1}-\alpha{\widehat{\mathrm{Ri}_{b}}} \\
& \mathscr{C}=-1,
\end{aligned}
$$

Obviously, for stability-dependent $C_{H, s}$ the solution depends on one more parameter, as compared to the solution for constant $C_{H, s}=C_{H n}$, namely on

$$
\widehat{\mathrm{Ri}_{b}}=\frac{g z}{\theta_{0}} \frac{\left(\theta_{\text {lead }}-\theta_{\mathrm{rad}}\right)}{U^{2}} .
$$

The quadratic equation, (20), has two solutions. One solution corresponds to a negative bulk Richardson number (unstable stratification). This is obviously unphysical because the used stability functions are valid only for nonnegative $\mathrm{Ri}_{b}$. The only physically valid solution is

$$
\overline{\Delta \theta}=\frac{-\mathscr{B}+\sqrt{\mathscr{B}^{2}-4 \mathscr{C C}}}{2 \mathscr{C}} .
$$

However, one should keep in mind that the number of solutions depends on the used stability functions. It was shown already by McNider et al. (1995) that the use of Businger-Dyer stability functions (or their $\mathrm{Ri}_{b}$ equivalent) in a simple model of a stable $\mathrm{ABL}$ results in multiple solutions for a certain range of external parameters, such as the geostrophic wind speed. This reflects a fundamental feature of the Monin-Obukhov similarity theory: the nonuniqueness of solutions of its equations in stable stratification (e.g., Malhi 1995; Holtslag et al. 2007; Van de Wiel et al. 2011, 2017). This nonlinear behavior was further studied in Derbyshire (1999), Van de Wiel et al. (2002), Shi et al. (2005), Walters et al. (2007), McNider et al. (2012), and Van de Wiel et al. (2012, 2017). In the latter work, it was clearly demonstrated that the use of the short-tail and cutoff stability functions in a model of a stable ABL, similar to the one presented here, results in the existence of multiple solutions in a certain range of wind speed. The authors also showed that long-tail stability functions do not produce several solutions. This is also the case for the long-tail Louis stability function, which we use.

Thus, one should keep in mind that the arbitrary choice of stability functions leads to an uncertainty of results, especially in the range of wind speed close to its transition value. However, a detailed analysis of this issue is outside of the scope of this paper, and the reader is referred to the existing literature (e.g., McNider et al. 1995, 2012; Van de Wiel et al. 2017) where this matter was considered in much detail.

In the following, the analytical solution with constant $C_{H, s}=C_{H n}$ given by (18) is referred to as CONST, while the one with stability-dependent $C_{H, s}$ given by (25) is referred to as STDP.

\section{Single-column numerical model}

In addition to the analytical model we apply also a single-column numerical model, which is a $1 \mathrm{D}$ version of the nonhydrostatic three-dimensional (NH3D) atmospheric model (Miranda and James 1992; Chechin et al. 2013) coupled to a sea ice/snow model. The atmospheric model consists of prognostic equations for the horizontal wind components $u$ and $v$ and potential temperature $\theta$. Vertical turbulent and longwave radiative fluxes are parameterized. The 1D snow/ice model consists of a prognostic heat diffusion equation. The atmospheric and snow/ice models are coupled by solving the heat balance equation at the snow surface.

Turbulent fluxes of heat and momentum above the surface layer are parameterized using a first-order local closure with

$$
\begin{aligned}
& \overline{w^{\prime} \theta^{\prime}}=-K_{H} \frac{\partial \theta}{\partial z} \\
& \overline{u^{\prime} w^{\prime}}=-K_{M} \frac{\partial u}{\partial z}
\end{aligned}
$$




$$
\overline{v^{\prime} w^{\prime}}=-K_{M} \frac{\partial v}{\partial z}
$$

For Ri $>0$ the eddy diffusivities $K_{M}$ and $K_{H}$ are given by

$$
\begin{aligned}
K_{M} & =\left|\frac{\partial \mathbf{U}}{\partial z}\right| l^{2}\left(1+5 \mathrm{Ri}+44 \mathrm{Ri}^{2}\right)^{-2}, \\
K_{H} & =K_{M},
\end{aligned}
$$

where $\mathrm{Ri}$ is the gradient Richardson number, $\mathbf{U}$ is the horizontal wind vector, and $l$ is the mixing-length scale. The latter is prescribed using the Blackadar formula (Blackadar 1962) with the maximum asymptotic value $l_{\max }=40 \mathrm{~m}$. It is realized that there exist more physically adequate formulations that were proposed for $l$ and $l_{\max }$ (e.g., Delage 1974; Therry and Lacarrère 1983; Van de Wiel et al. 2008; Sorbjan 2014). Although simulation results are sensitive to the choice of a closure for $l_{\max }$, this has a minor impact on the main conclusions of the study.

The stability function in (30) closely approximates the universal function of Beljaars and Holtslag (1991), which uses $z / L$ as a stability parameter. The Ri-based approximation in (30) was used earlier by Savijärvi (2009) in his simulations of a stable boundary layer in the Antarctic and results were shown to be in good agreement with observations. Using the Businger-Dyer stability functions in a form with $\mathrm{Ri}$ as a stability parameter [as it was done, for example, by Vihma et al. (2003) in their simulations of a stable ABL over sea ice] does not change qualitatively the results of our 1D simulations.

Test simulations of the first GEWEX Atmospheric Boundary Layer Study (GABLS1) case (Cuxart et al. 2006), which represents a weakly stable Arctic ABL, showed that the $1 \mathrm{D}$ model in the described configuration produced results in a good agreement with large-eddy simulations (not shown here). Also, the NH3D model previously successfully reproduced vertical profiles of wind speed and temperature over the Arctic sea ice and the marginal sea ice zone (Chechin et al. 2013).

For the sea ice concentration $A<1$, the surface heat and momentum fluxes ( $H$ and $\tau$, respectively) are aggregated over sea ice and leads using the tile (mosaic) approach, namely,

$$
\begin{gathered}
H_{\text {total }}=A H_{\text {ice }}+(1-A) H_{\text {lead }}, \\
\tau_{\text {total }}=A \tau_{\text {ice }}+(1-A) \tau_{\text {lead }} .
\end{gathered}
$$

Surface fluxes in (32) and (33) are parameterized using Monin-Obukhov similarity theory. Thereby, we are using the universal functions proposed by Grachev et al. (2007) on the basis of the SHEBA observations. Note the inconsistency between the stability functions used in the 1D model and in the analytical model. Our methodology is that the $1 \mathrm{D}$ model represents a more complete and a more realistic model, as compared to the analytical model. Thus, in the 1D model, the universal functions based on observations are used, unlike the Louis functions in the analytical model. For the calculation of fluxes, the same values of wind speed $U$ and $\theta$ at the lowest model level (4-m height) are used over both leads and sea ice. The lead surface temperature is set to $271.35 \mathrm{~K}$ following Lüpkes et al. (2008b). The roughness length $z_{0 m}$ is set to $10^{-3}$ and $10^{-4} \mathrm{~m}$ over sea ice and leads, respectively though it is realized that nonconstant parameterizations for $z_{0}$ exist over water (e.g., Charnock formula). For the roughness length for heat we use $z_{0 t}=0.1 z_{0 m}$ both over leads and sea ice.

The longwave radiative fluxes in the $\mathrm{ABL}$ and at the surface are calculated using the radiative transfer model developed at the Goddard Climate and Radiation Branch (Chou et al. 2001). This results in more realistic radiative cooling and heating rates compared to the empirical formula used in Lüpkes et al. (2008b). In the Goddard scheme, the $\mathrm{CO}_{2}$ volume mixing ratio is set to 360 ppmv, which is the same value as used in the study of the Arctic air-mass formation by Pithan et al. (2016).

For simplicity, specific humidity is set to $80 \%$ of its saturation value over ice. This does not allow for condensation and cloud formation, as the focus is on clearsky conditions.

The sea ice/snow model consists of the prognostic heat diffusion equation

$$
\rho_{i, s} c \frac{\partial T_{i, s}}{\partial t}=k_{i, s} \frac{\partial^{2} T_{i, s}}{\partial z^{2}},
$$

where $k_{i, s}$ are the constant thermal conductivities for ice and snow, respectively; $\rho_{i, s}$ is the constant ice and snow density ( 916 and $290 \mathrm{~kg} \mathrm{~m}^{-3}$, respectively); and $c$ is the heat capacity of ice set to $2100 \mathrm{~J} \mathrm{~kg}^{-1} \mathrm{~K}^{-1}$.

At the top of the snow layer the heat balance equation

$$
R_{\text {up }}+R_{\text {down }}+F_{s}=H_{\text {ice }}
$$

is solved iteratively to obtain the surface temperature. Variables $R_{\text {up }}$ and $R_{\text {down }}$ are the upwelling and downwelling longwave radiative fluxes, respectively, and $F_{s}$ is the conductive flux in the highest level in the snow. The term $R_{\text {up }}+R_{\text {down }}$ is calculated within the Goddard radiative scheme.

At the snow-ice interface the following boundary condition is used

$$
\left.T_{s}\right|_{z=h_{s}}=\left.T_{i}\right|_{z=h_{s}},
$$




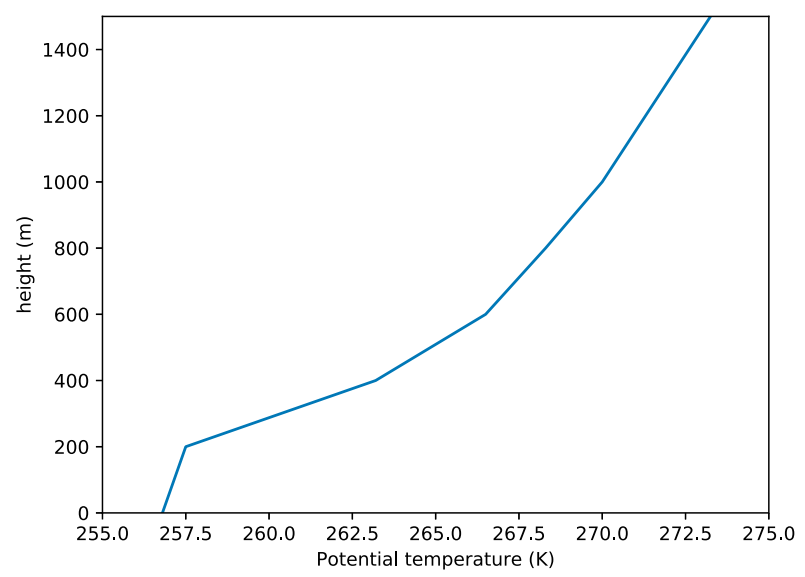

FIG. 2. Potential temperature profile based on the radiosounding launched at NP-37 on 11 November 2009.

$$
k_{s} \frac{\partial T_{s}}{\partial z}=k_{i} \frac{\partial T_{i}}{\partial z}
$$

where $h_{s}$ is the thickness of the snow layer. At the lower boundary of the ice layer a constant temperature $T_{w}=$ $271.35 \mathrm{~K}$ is prescribed.

The setup of the 1D model experiments is similar to the one used in Lüpkes et al. (2008b). We initialize the model with a profile of potential temperature observed by radiosounding at the NP-37 station on 11 November 2009 in cloudy conditions several hours before the sky cleared (Fig. 2). The profile is slightly stable up to the height of about $200 \mathrm{~m}$ with the ABL-averaged potential temperature equal to about $257 \mathrm{~K}$. A strong inversion above the mixed layer is occupying the layer between 200 and $600 \mathrm{~m}$ with a temperature jump of about $10 \mathrm{~K}$ across this layer.

The model is forced by geostrophic wind, which is assumed to be constant in height and time. Initial values of the horizontal wind components are set equal to those of the geostrophic wind. The model is integrated for the period of 12 days.

In all experiments, constant sea ice and snow thickness of 2 and $0.3 \mathrm{~m}$, respectively, are used. The same values were used in Lüpkes et al. (2008b) as representative values for a central Arctic.

The vertical grid spacing of $8 \mathrm{~m}$ is used in the atmosphere with the lowest level at $4 \mathrm{~m}$ height. We use 25 levels in the ice slab and 15 levels in the snow slab. That many levels in the snow and ice layers are used to be sure that vertical resolution is sufficient.

\section{Observations}

We use in this study near-surface observations performed at three Russian North Pole drifting stations and during the SHEBA campaign. Measurements at the SHEBA Flux Tower are presented in much detail elsewhere (e.g., Persson et al. 2002), so in the following, only the observations at the NP stations are described.

At the NP stations, wind speed and direction, as well as air temperature (also relative humidity, which is not used in this study) were measured by an automatic weather station MAWS 110 (Vaisala). At the NP-35 and NP-37 stations, air temperature was observed at 2- and 8-m height, while at the NP-39 station only at 2-m height. The wind speed observations at $10-\mathrm{m}$ height are used in this study. Upward and downward shortwave and longwave radiative fluxes were observed at 2-m height using a Kipp and Zonen net-radiometer CNR-1 at NP-35 and NP-37, and CNR-4 (which replaced CNR-1 in the Kipp and Zonen product range and has very similar characteristics) at NP-39.

The surface temperature at the NP stations was calculated from the observations of the longwave radiative fluxes using

$$
T_{s}=\left[\frac{R_{\mathrm{up}}-\left(1-\varepsilon_{s}\right) R_{\mathrm{down}}}{\varepsilon_{s} \sigma}\right]^{1 / 4},
$$

where for the surface emissivity the value $\varepsilon_{s}=0.98$ was used, which is consistent with the value used in the analytical model [(8) and (9)].

All observations at the NP stations were acquired with a temporal resolution of $1 \mathrm{~min}$. After applying the quality control procedures the data were averaged over 1-h intervals. Temperatures at multiple levels and at the surface were plotted against each other in order to estimate the consistency of data and to identify outliers, which were further checked. This helped, for example, to identify periods when the infrared radiometer did not function correctly, probably due to icing. In this study, data with wind speed lower than $0.1 \mathrm{~m} \mathrm{~s}^{-1}$ at 2-m height were excluded from the analysis, as well as the cases when wind speed at $10 \mathrm{~m}$ height was lower than wind speed at 2-m height.

Only the situations with clear sky were selected. The selection criterion was based on the value of the net longwave radiation $\mathrm{LW}<-20 \mathrm{~W} \mathrm{~m}^{-2}$, similar to Stramler et al. (2011) who used the criterion $\mathrm{LW}<-30 \mathrm{~W} \mathrm{~m}^{-2}$. We chose the lower threshold value (in absolute sense) to make sure that cases with strong inversions are not filtered out. Our criterion was validated by a comparison with visual observations of cloud fraction carried out every $3 \mathrm{~h}$ at the NP stations.

In this study, only the polar night period is considered: from the beginning of November until the end of February. Fig. 3 shows the drift trajectories (in blue) of the three NP stations during this period. The NP-35 drift 


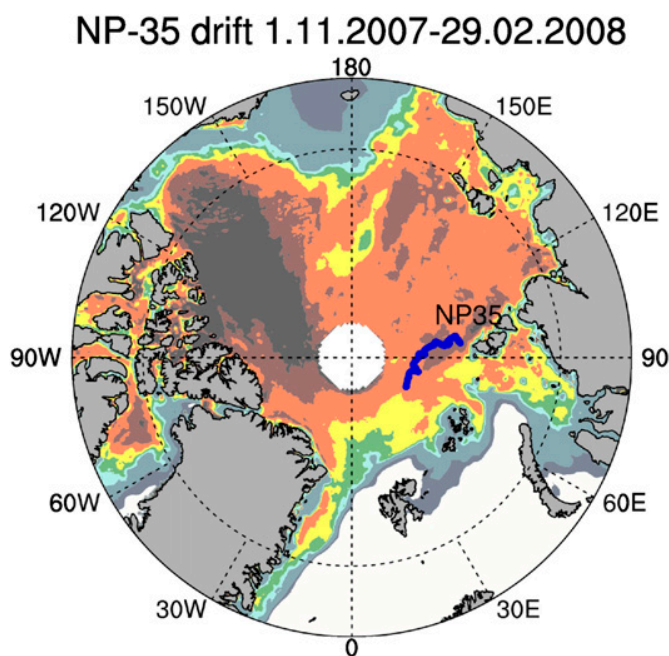

NP-39 drift 1.11.2011-29.02.2012

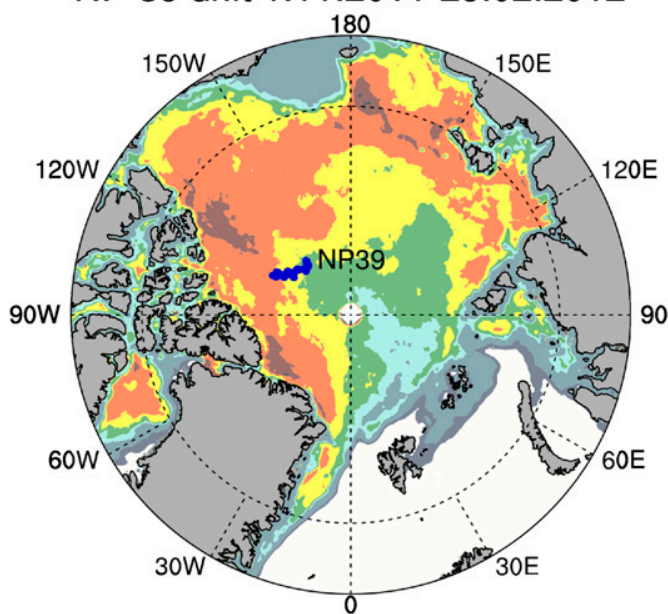

NP-37 drift 1.11.2009-28.02.2010

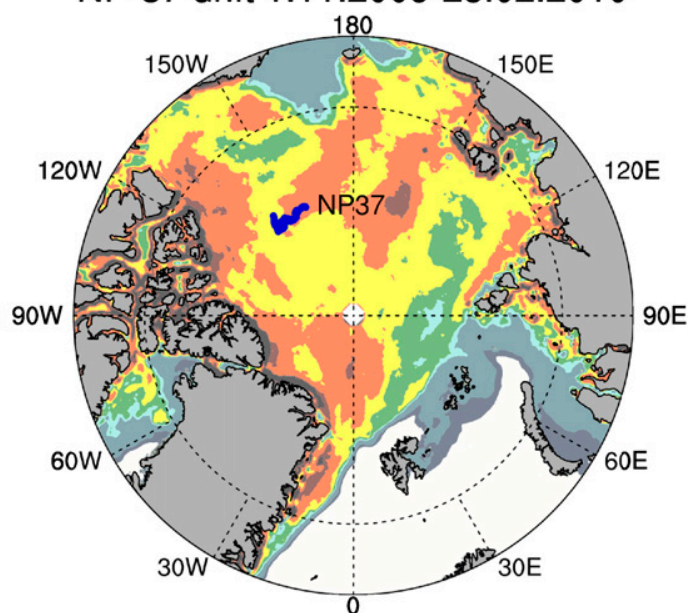

SHEBA drift 1.11.1997-28.02.1998

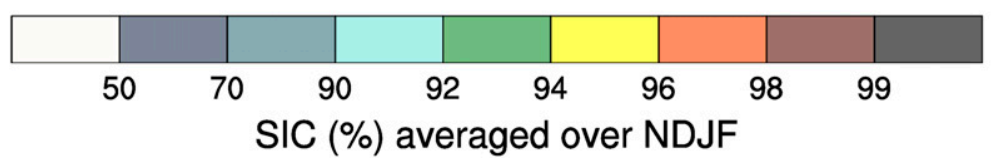

FIG. 3. Drift trajectories of the (top left) NP-35 (2007-08), (top right) NP-37 (2009-10), (bottom left) NP-39 (2011-12), and (bottom right) SHEBA (1997-98) stations over the period of November-February overlaid on the sea ice concentration averaged over the same period based on SSM/I data (Integrated Climate Date Center, University of Hamburg, Hamburg, Germany, https://icdc.cen.uni-hamburg.de/). Each trajectory start is marked with the station name.

is located in the Atlantic sector of the Arctic to the north from the Kara and Barents Seas. NP-37 and NP-39 drifted closer to the Canadian basin and Beaufort Gyre. The difference in the geographical location results in different background meteorological conditions as well as in different values of the sea ice parameters around the stations. The presentation and detailed analysis of such differences is beyond the scope of this paper and is left for further research.

To give a rough estimate of possible SIC values around the stations, the SIC fields derived from the
Special Sensor Microwave Imager (SSM/I) and Special Sensor Microwave Imager/Sounder (SSM/IS) data (https://icdc.cen.uni-hamburg.de/; Kaleschke et al. 2001) are presented in Fig. 3. Drift trajectories are overlaid over the SIC fields averaged over the NovemberFebruary period of the corresponding polar-night season. Evidently, SIC rarely reaches exactly $100 \%$. However, as shown previously by Tetzlaff et al. (2013), there is a significant uncertainty of the satellite-derived SIC in the range between $90 \%$ and $100 \%$, which is the focus of our study. In particular, Tetzlaff et al. (2013) 


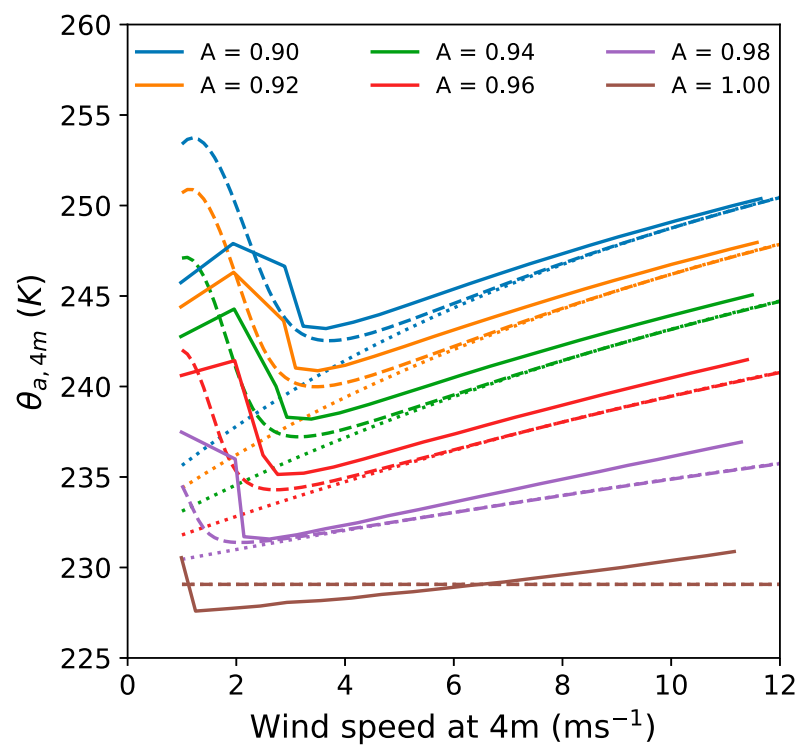

FIG. 4. Air temperature at $4 \mathrm{~m}$ as function of the sea ice concentration and wind speed at $4 \mathrm{~m}$, as produced by the $1 \mathrm{D}$ model after 12 days of cooling (solid lines) and the steady-state solutions: CONST with constant $C_{H, s}=C_{H n}$ (dotted lines) and STDP with stability-dependent $C_{H, s}$ (dashed lines).

show that the SSM/I-SSM/IS product shown in Fig. 3 might underestimate SIC in this range.

\section{Analytical solutions and $1 D$ model results}

The 1D model is run with a sea ice concentration $A$ ranging from 0.9 to 1 and the geostrophic wind speed ranging from 1 to $20 \mathrm{~m} \mathrm{~s}^{-1}$ for 12 days. The results for $\theta_{a}$ at 4-m height after 12 days of simulation are presented in Fig. 4 together with the steady-state solutions using constant $C_{H, s}$ (CONST) and stability-dependent $C_{H, s}$ (STDP). First of all, a strong sensitivity of $\theta_{a}$ to $A$ is produced by the 1D model and both steady-state solutions, which is in agreement with the earlier results by Lüpkes et al. (2008b). For $A$ changing from 1 to 0.9 , a warming of about $15-20 \mathrm{~K}$ is obtained, depending on the wind speed.

The sensitivity of $\theta_{a}$ to wind speed is nonmonotonic, as indicated by the 1D model and the STDP solution. Namely, the lowest temperatures are obtained for the threshold value of wind speed $U_{\text {tr }}$ of about $2-4 \mathrm{~m} \mathrm{~s}^{-1}$. The value of the latter depends on the sea ice concentration and is larger for smaller $A$. The values of $U_{\mathrm{tr}}$ in the STDP solution and, moreover, their sensitivity to $A$ are in good agreement with the 1D model results.

Similar nonmonotonic dependency of $\theta_{a}$ on $U$ was found in observations both over the Arctic sea ice (Lüpkes et al. 2008b) and over the South Pole (Hudson and Brandt 2005) and also in the idealized 1D simulations (Lüpkes et al. 2008b; McNider et al. 2012; Sterk et al. 2013; Savijärvi 2014).

For $U>U_{\mathrm{tr}}, \theta_{a}$ is growing with increasing $U$. In the steady state, the reason is that the heat flux from leads is increasing with $U$ and warms both the air and the sea ice surface as a whole. This dependency is well captured by both the CONST and STDP solutions. They almost completely coincide in the range $U>U_{\text {tr }}$, as stability plays minor role for high wind speed.

For $U<U_{\mathrm{tr}}, \theta_{a}$ is increasing with decreasing $U$ in STDP and also in the 1D model results. Also, in both models, for very weak wind there is again a very slight decrease of $\theta_{a}$. The mechanism leading to the temperature increase at low wind speed can be better understood if we first consider the effect of stability on $C_{H, s}$ and $\Delta \theta=\theta_{a}-\theta_{s}$.

Figure 5 shows the values of $C_{H, s}$ and of $\Delta \theta=\theta_{a}-\theta_{s}$ as functions of $U$ and $A$ obtained from the 1D model results and analytical solutions. Clearly, for $U=U_{\text {tr }}$ a rapid decrease of $C_{H, s}$ occurs, which is accompanied by a rapid increase of $\Delta \theta$. This is a manifestation of a positive feedback resulting in a "jump-like" growth of stability (e.g., Derbyshire 1999; Van de Wiel et al. 2017). Namely, the transition to the strongly stable regime (i.e., decoupling) occurs when the turbulent transport over sea ice is suppressed by stability and becomes not sufficient to compensate the heat flux (advection) from leads.

Both the heat fluxes over snow and leads decrease almost linearly with decreasing wind as follows from (1). However, additionally to this effect, heat loss from air to snow is further reduced due to stability. To reach a new equilibrium, $\Delta \theta$ increases as the air warms. The heat flux over leads is not diminished by stability. On the contrary, in reality decreasing wind would result in stronger convective transport over leads. This effect is not included in the analytical model, but is present in the 1D model. Thus, the effect of stability on $C_{H, s}$ and also the presence of leads have a governing role in transition to the strongly stable regime in the 1D model and in the STDP solution. It is not surprising that the CONST solution does not reproduce this transition.

When the sea ice concentration is decreasing, the heating from leads is increasing and the transition to the strongly stable regime occurs already at larger $U$ both in the 1D model and in STDP. Also, from Fig. 5 it can be seen that $\Delta \theta$ and stability over sea ice are increasing when $A$ is decreasing. Thus, our solutions highlight the important role of leads whose presence amplifies the decoupling. This is a specific feature of a stable ABL over sea ice, which makes it different from a nocturnal ABL in midlatitudes or a stable ABL over the Antarctic Plateau.

The effect of leads is further demonstrated by Fig. 6, where the main $\mathrm{ABL}$ heat budget terms are shown. 

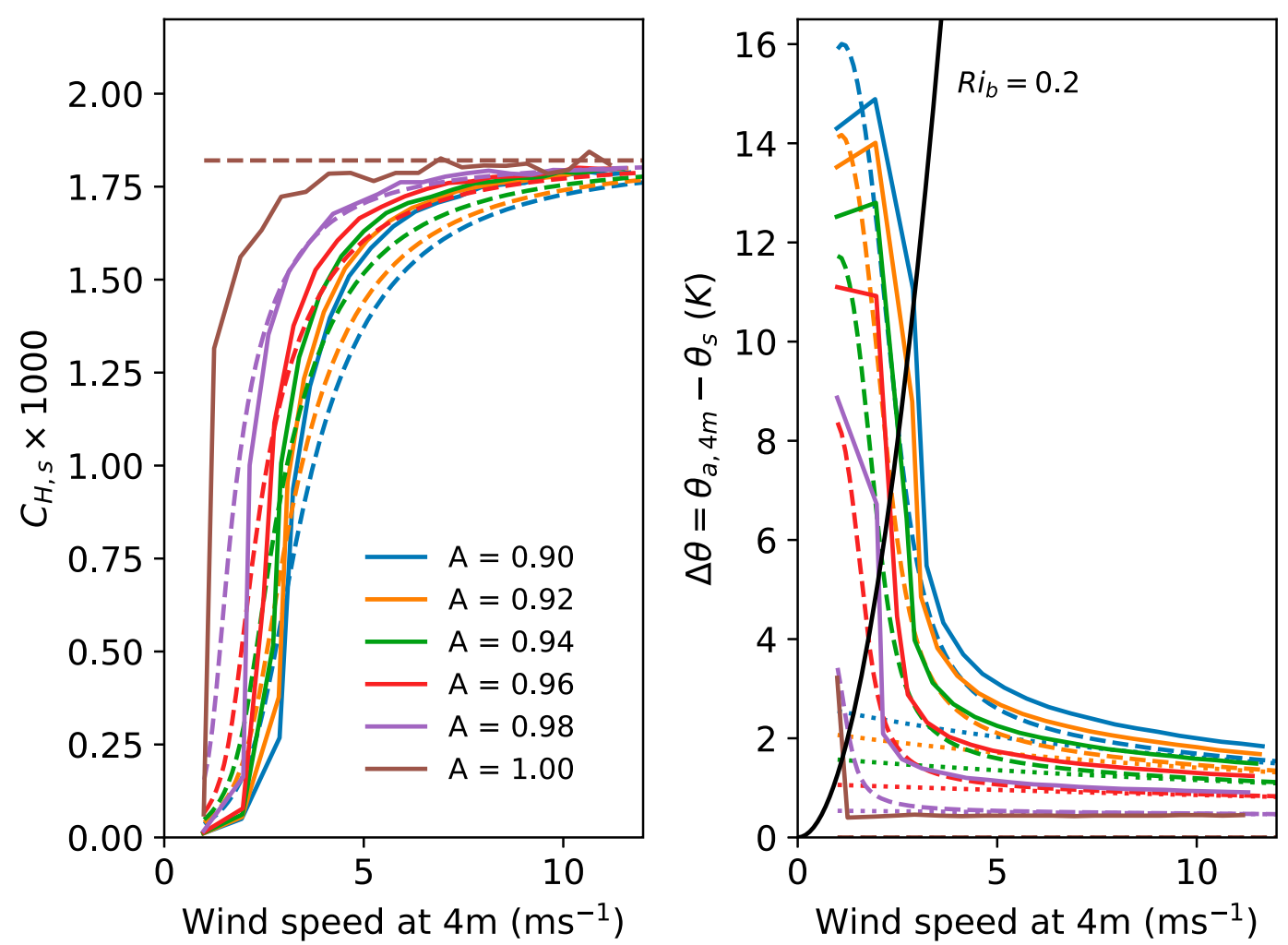

FIG. 5. (left) Exchange coefficient for heat over sea ice $C_{H, s}$ and (right) temperature difference $\Delta \theta=\theta_{a}-\theta_{s}$ as function of wind speed and sea ice concentration $A$ based on the 1D solutions after 12 days of cooling (solid lines) and the steady-state solutions: CONST with constant $C_{H, s}=C_{H n}$ (dotted lines) and STDP with stability-dependent $C_{H, s}$ (dashed lines). The black solid line in the right panel corresponds to $\Delta \theta$ and wind speed values for which $\mathrm{Ri}_{b}=0.2$. To the left of this line, $\mathrm{Ri}_{b}>0.2$.

The latter are the surface turbulent fluxes $A H_{\text {ice }}$ and $(1-A) H_{\text {lead }}$ (entrainment at the ABL top is neglected) and the difference between the net radiative flux at the ABL top $R_{h}$ and the ABL bottom $R_{s}$. There, the results of the 1D model and the STDP solution are shown for $A=0.96$. The figure shows that in the 1D model results there is an approximate balance between $A H_{\text {ice }}$ and $(1-A) H_{\text {lead }}$ for $U>U_{t r}$. In this range of $U$, the longwave flux divergence is small relative to the surface turbulent fluxes. Note that for $U>U_{\text {tr }}$ there is net radiative warming of the ABL due to the presence of a strong inversion at the ABL top. In contrast, in the decoupled regime, for $U<U_{\text {tr }}$ there is another balance: warming due to leads is compensated rather by the radiative cooling, while the turbulent heat flux over the ice is negligibly small. The analytical solution qualitatively agrees with the 1D model results, although both the heating from leads and the longwave cooling are underestimated. This is due to the use of the constant neutral $C_{H, w}$ in the analytical model. In the $1 \mathrm{D}$ model, $C_{H, w}$ values are increased due to unstable stratification over leads.

Clearly, Fig. 6 shows that turbulent heat flux over sea ice depends on wind speed. Moreover, we found that another important component of the surface energy balance strongly indirectly depends on wind speed, namely, the net longwave radiative flux LW. Figure 7 shows LW as function of $U$ according to the $1 \mathrm{D}$ model results. In particular, LW becomes more negative with increasing wind speed, from about -20 to -50 to $-60 \mathrm{~W} \mathrm{~m}^{-2}$ for $U$ changing from 1 to about $12 \mathrm{~m} \mathrm{~s}^{-1}$. This is related to two factors: 1) the inversion strength decreasing with increasing $U$ and 2) the ABL height increasing with $U$, which makes the ABL optically thicker for the longwave radiation emitted by the inversion layer.

Figure 7 also shows that LW depends on the sea ice concentration. For $A$ changing from 0.9 to 1 , the absolute value of $\mathrm{LW}$ is on average decreasing by about $20 \mathrm{~W} \mathrm{~m}^{-2}$. This has to do with the ABL warming by leads, which is reducing the inversion strength and increasing the ABL height.

A further understanding of the dependency of LW on $U$ and $A$ can be obtained by considering the heat balance equation, (3), at the surface. Larger $U$ and smaller $A$ result in a larger turbulent heat flux directed from the ABL to the snow surface. According to (3), the increased turbulent heat flux has to be compensated by an 


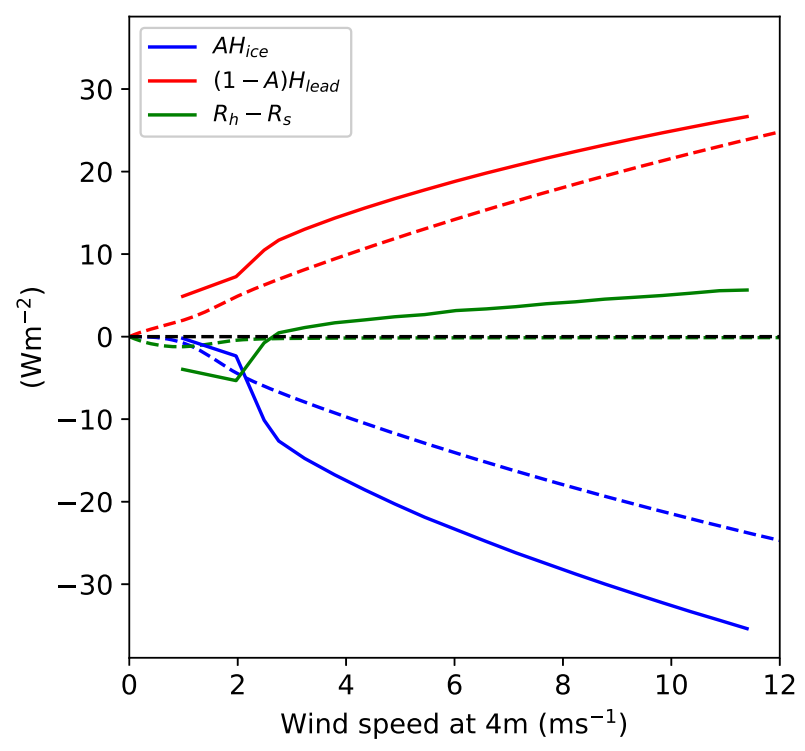

FIG. 6. The ABL heat budget components for $A=0.96$ as produced by the $1 \mathrm{D}$ model (solid lines) after 12 days of cooling and the STDP solution (dashed lines) as functions of wind speed: heat flux from leads $(1-A) H_{\text {lead }}$ (red lines), heat flux into the sea ice $A H_{\text {ice }}$ (blue lines), and the net longwave radiative flux divergence $R_{h}-R_{s}$ (green lines).

increase of LW and a decrease of the conductive heat flux.

The sensitivity of LW to wind speed and $A$ manifests a negative feedback in the coupled ABL-sea ice system. Namely, at low wind speed (or high $A$ ) LW becomes less negative and does not allow the ABL to cool too much, while at higher wind speed (or lower $A$ ) LW becomes more negative and does not allow too much warming due to the heat flux from leads. Thus, this feedback decreases the sensitivity of $\theta_{a}$ to $U$ and $A$.

Figure 7 also shows that the described dependency of $\mathrm{LW}$ on $U$ and $A$ is to a large extent taken into account by the modified KLA parameterization, (9). Namely, Fig. 7 shows the values of LW computed by the $1 \mathrm{D}$ model with the Goddard scheme and by the modified KLA using in (9) $\theta_{a}$ and $\theta_{s}$ taken from the 1D model results. Despite a good agreement, one should realize that the modified KLA parameterization is rather simple and does not contain an explicit dependency of $R_{\text {down }}$ on the ABL height.

In this section it was shown that in the steady state the presence of leads results in a nonmonotonic dependency of $\theta_{a}$ on $U$. In several studies the same dependency was obtained also for the nocturnal stable boundary layer over land (McNider et al. 2012; Savijärvi 2014) and for the Arctic ABL with no leads (Sterk et al. 2013). The simulations in those studies were run typically for $9 \mathrm{~h}$. By the end of $9 \mathrm{~h}$, the cooling is still in progress and the steady state with respect to the ABL temperature is not reached. Savijärvi (2014) suggested that the ABL cooling time scale depends nonmonotonically on $U$ and this, in turn, explains the dependency of $\theta_{a}$ on $U$. In particular, at low wind speed the ABL cooling is slowed down due to a decrease of the turbulent heat exchange with the surface.

Concerning the strong wind regime, none of the mentioned studies considered the ABL cooling time scale in detail. It was suggested (McNider et al. 2012; Sterk et al. 2013) that the increase of $\theta_{a}$ with $U$ in the strong wind regime can be explained by a stronger turbulent coupling between the ABL and the outer atmosphere. Thereby, a warmer air is entrained into the ABL from aloft and is transported down to the surface. Lüpkes et al. (2008b) formulated it slightly differently, suggesting that stronger wind results in a thicker ABL and it takes longer to cool it, as compared to a shallower $\mathrm{ABL}$ at lower wind speed. Despite those efforts, there is lack of systematic studies on this matter. Thus, we address this problem in appendix B. Using a simple model, we discuss several factors affecting the ABL cooling time scale in the strong wind regime. It is important that we consider a long-living stable $\mathrm{ABL}$ and therefore interested in time scales longer than those that are typical for nocturnal cooling. We show that in the strong wind regime, there are several ways how $U$ affects the cooling time scale. These are 1) the dependency of the ABL height on wind speed, 2) the dependency of the surface heat flux on wind speed, and 3) the dependency on wind speed of the thermal coupling between the ABL and the snow-ice layer.

In appendix $\mathrm{B}$, we show analytically that the $\mathrm{ABL}$ cooling time scale is increasing with $U$ in the strong wind regime due to the interaction of the above mentioned processes. In particular, we found that stronger thermal coupling between the ABL and the snow-ice layer results in longer cooling time scale. We do not discuss the increase of the cooling time scale in the weak wind regime due to an increase of stability, as it was well documented previously (e.g., McNider et al. 2012).

\section{Comparison with observations}

Figure 8 shows the observed $\theta_{a}$ as a function of wind speed at 10-m height (2-m height for NP-39) during clear sky. For the comparison with the model solutions we consider the coldest temperatures shown by the shaded area between the 10th- and 50th-percentile curves. The percentile values were calculated for data binned into intervals with the width of $1 \mathrm{~m} \mathrm{~s}^{-1}$. We believe that such a selection better represents the final stages of clear-sky cooling and thus could be compared with our 

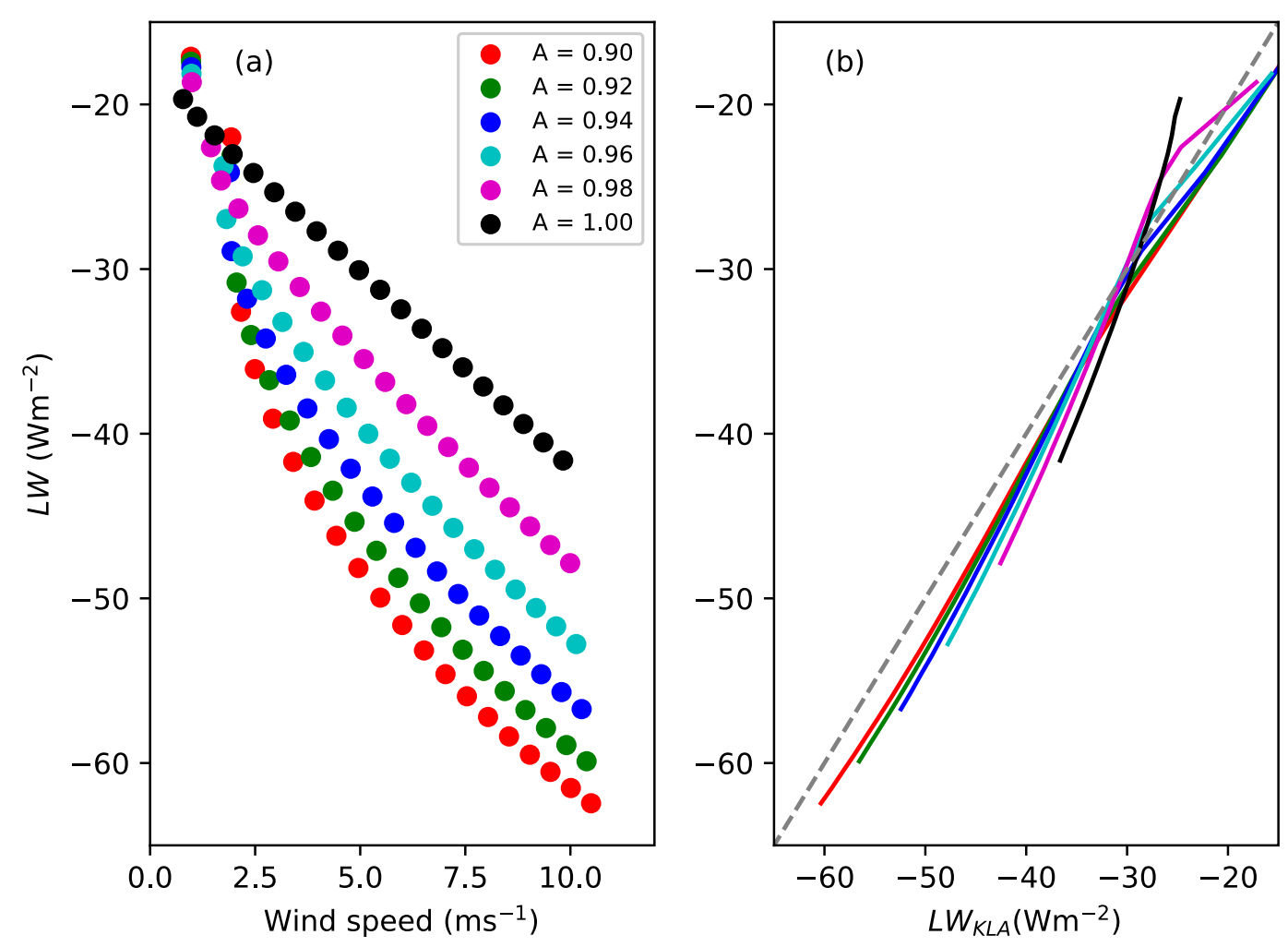

FIG. 7. (a) The net longwave radiative flux at the sea ice surface as function of wind speed at 4-m height. (b) The modified König-Langlo and Augstein parameterization against the 1D model results using the Goddard scheme after 4 days of cooling with the geostrophic wind ranging from 1 to $20 \mathrm{~m} \mathrm{~s}^{-1}$ and $A$ ranging from 0.9 to 1 .

model results. The model curves shown in Fig. 8 are obtained for $A=0.96$ in both the $1 \mathrm{D}$ and analytical models. Note that Fig. 8 shows the model results for $\theta_{a}$ and $U$ at 4-m height.

Figure 8 shows the pronounced dependency of the lowermost $\theta_{a}$ on wind speed at all the three NPs and SHEBA. The lowest temperatures almost linearly increase with increasing $U$ for wind speed greater than $3-4 \mathrm{~m} \mathrm{~s}^{-1}$. The analytical and 1D solutions fit the lowest observed temperatures quite well in this range of wind speed. For wind speed smaller than $3-4 \mathrm{~m} \mathrm{~s}^{-1}$ the observed minimal $\theta_{a}$ does not further decrease with wind speed and might even slightly increase with decreasing wind, especially at NP-35 and SHEBA. Thus, observations at least do not contradict the modeled nonmonotonic dependency of $\theta_{a}$ on $U$.

Figure 9 shows the observed $\Delta \theta$ as function of wind speed. Clearly, large values of $\Delta \theta$ are observed at low wind speed similar to other observations in stable ABLs (e.g., Vignon et al. 2017) and only small values of $\Delta \theta$ at stronger winds. Also, as expected in the stable ABL, the values of $\theta_{a, 8 \mathrm{~m}}-\theta_{s}$ exceed those of $\theta_{a, 2 \mathrm{~m}}-\theta_{s}$. The strongest increase of $\Delta \theta$ for decreasing wind speed was observed at NP-37. There, the values of $\theta_{a, 8 \mathrm{~m}}-\theta_{s}$ can exceed $10 \mathrm{~K}$ for low winds. Slightly smaller values of $\theta_{a, 8 \mathrm{~m}}-\theta_{s}$ rarely exceeding $8 \mathrm{~K}$ at low winds were observed at NP-35 and SHEBA. The analytical and 1D model solutions with respect to $\Delta \theta$ are not in contradiction with observations at NP-35, NP-37, and SHEBA, though the spread in observations is large to take definite conclusions. The maximum values of $\Delta \theta$ simulated by the $1 \mathrm{D}$ model are about 12 and about $7 \mathrm{~K}$ by the STDP solution, which is comparable with the observed values.

At NP-39, the values of $\theta_{a, 2 \mathrm{~m}}-\theta_{s}$ show a very moderate increase at low winds and do not exceed $4 \mathrm{~K}$. No threshold wind speed separating the coupled and decoupled regime can be found in the NP-39 dataset. For other stations, such threshold wind speed value is about $4 \mathrm{~m} \mathrm{~s}^{-1}$ and is larger for $\theta_{a, 8 \mathrm{~m}}-\theta_{s}$ than for $\theta_{a, 2 \mathrm{~m}}-\theta_{s}$. The dependency of the threshold wind speed on height was also found in the nocturnal stable boundary layer by Sun et al. (2012). The absence of decoupling at NP-39 might be caused by larger surface roughness (see appendix A). The latter is increased over deformed multiyear ice to the north of the Canadian Archipelago, as shown by Petty et al. (2017), which is the region of the NP-39 drift. According to Castellani et al. (2014) and Petty et al. (2017) 

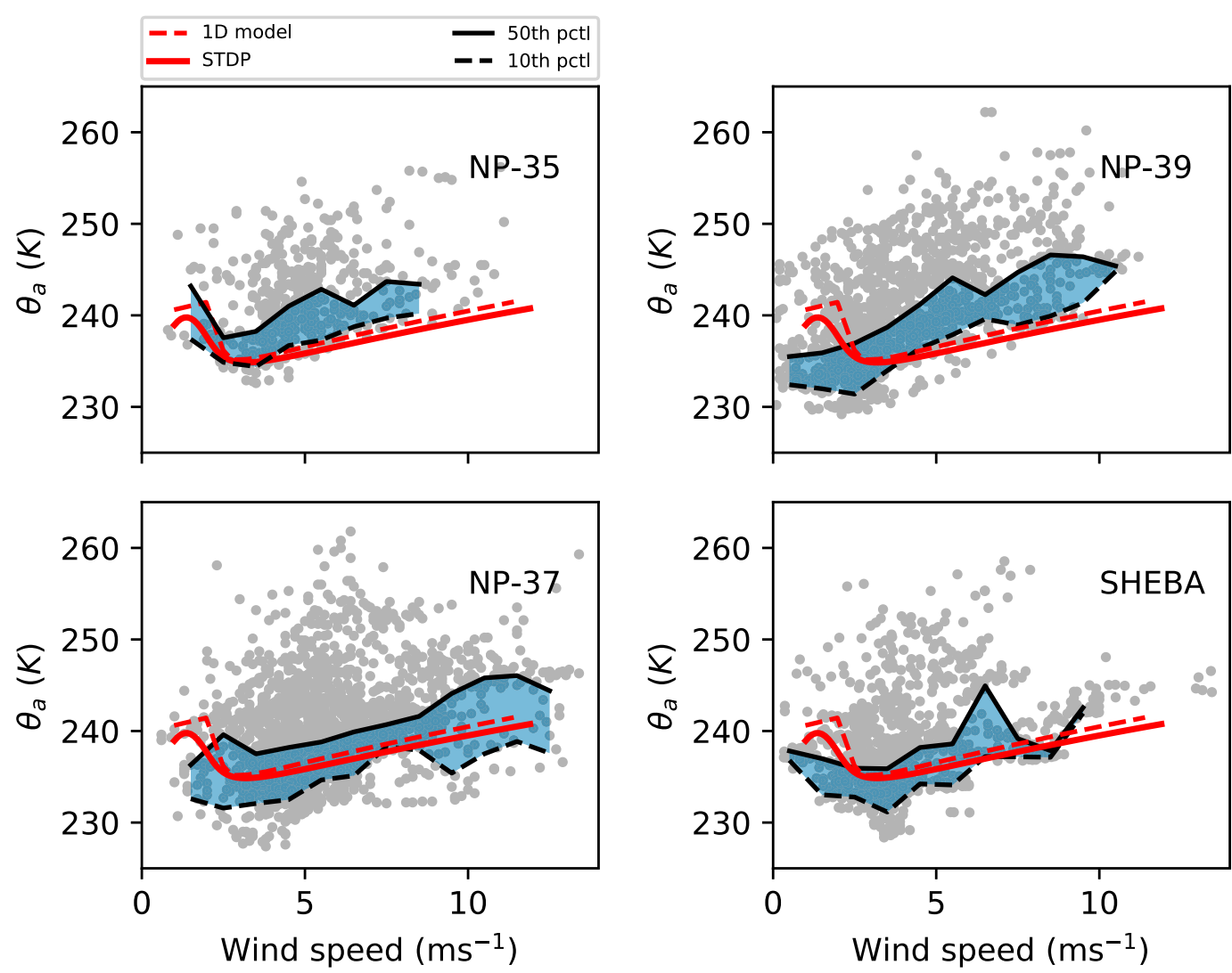

FIG. 8. Observed and modeled potential temperature as a function of wind speed. Gray circles represent the

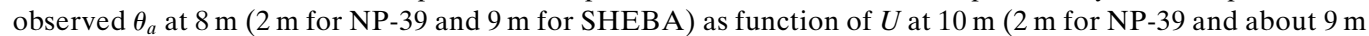
for SHEBA). Red lines show $\theta_{a}$ at $4 \mathrm{~m}$ as function of $U$ at $4 \mathrm{~m}$ as simulated by the $1 \mathrm{D}$ model after 12 days of cooling (dashed line) and as given by the STDP analytical solution (solid line). The area between the 10th- and 50th-percentile curves based on observations is shaded with blue.

the neutral drag coefficient there can be more than twice as large as that over the smoother first-year sea ice in the rest of the Arctic.

It is worth to note that the observed $\Delta \theta$ values for low wind speed are smaller than those observed at the Dome $\mathrm{C}$ station on the high East Antarctic Plateau, where $\theta_{10 \mathrm{~m}}-\theta_{s}$ can exceed $25 \mathrm{~K}$ (Vignon et al. 2017). One reason is a larger amount of water vapor over sea ice compared to the elevated Dome $\mathrm{C}$ location resulting in stronger radiative coupling of the atmosphere to the sea ice surface. Another possible reason is that the ocean under sea ice might serve as a source of heat. In addition, recent studies demonstrated the important contribution of the large-scale subsidence to the generation of strong inversions over the Antarctic Plateau (Baas et al. 2018; Vignon et al. 2018).

The observed values of $\Delta \theta$ shown in Fig. 9 are obtained using the surface potential temperature. The values of the latter contain some uncertainty related to the unknown and variable snow emissivity. This uncertainty can introduce scatter in $\Delta \theta$, but can be avoided by considering the observed values of $\theta_{8 \mathrm{~m}}-\theta_{2 \mathrm{~m}}$, as shown in Fig. 10. Less scatter is expected because identical temperature sensors are used at the two heights. Indeed, such presentation shows more clearly the transition between the strongly and weakly coupled regimes. It further demonstrates that decoupling at NP-37 was stronger and occurred at larger wind speed compared to NP-35 and SHEBA.

From Figs. 9 and 10 it is obvious that the observed scatter of $\Delta \theta$ is larger at low wind speed. Earlier studies (e.g., McNider et al. 1995, 2012; Van de Wiel et al. 2017) suggest that multiple equilibria associated with different values of $\Delta \theta$ can exist for a given wind speed, especially in the range of wind speed close to the transition between the strongly and weakly stable states. The existence of multiple equilibria and abrupt transitions between them might explain the large scatter of $\Delta \theta$ at low wind speed.

An important result obtained from the 1D model is the dependency of the net longwave radiative flux (LW) at the surface on wind speed $U$. Figure 11 shows that such a dependency exists also in the observations. To demonstrate this we calculated the 10th and 50th 


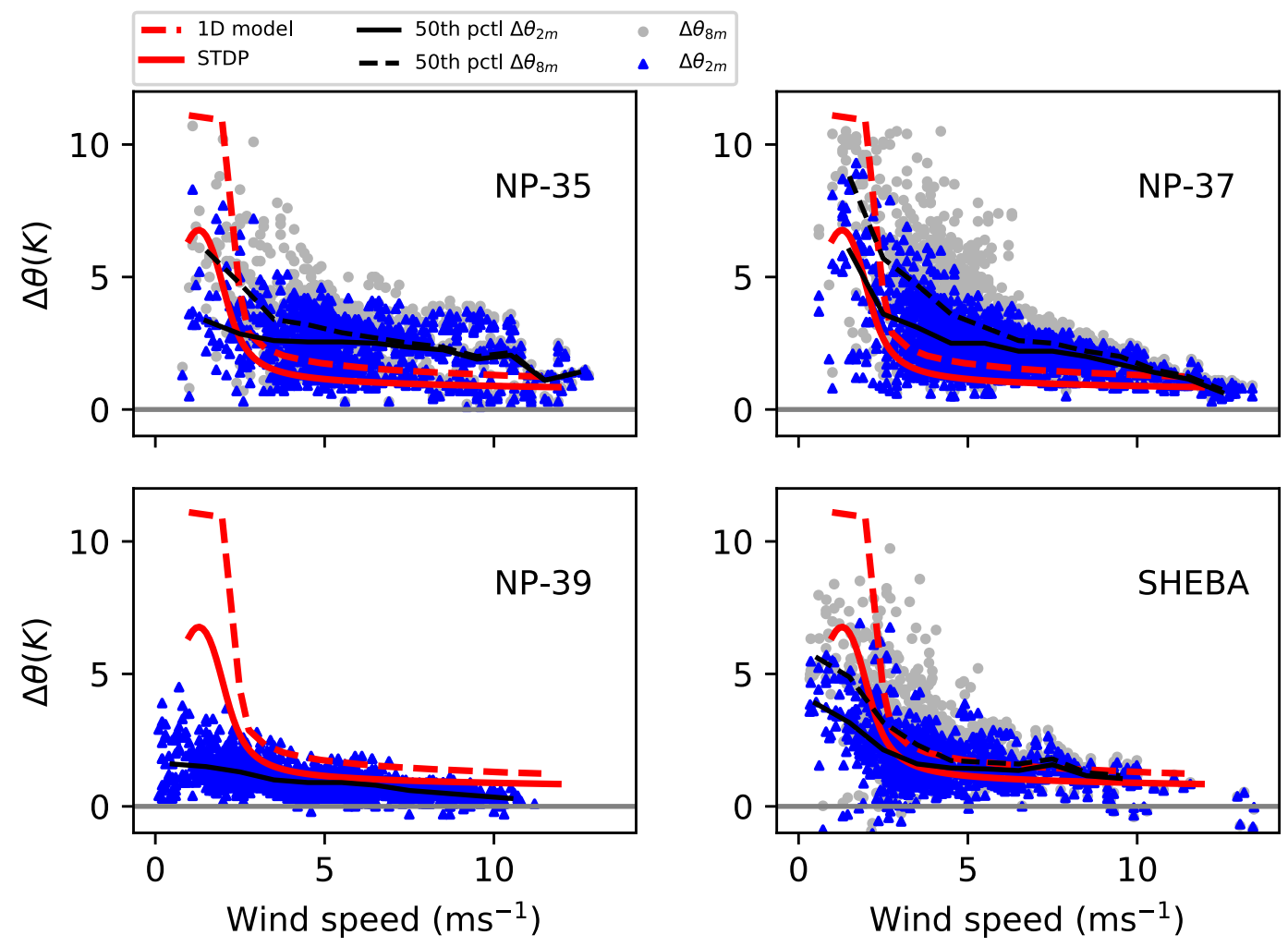

FIG. 9. Observed and modeled $\Delta \theta=\theta_{a}-\theta_{s}$ as a function of wind speed. Gray circles represent $\theta_{a, 8 \mathrm{~m}}-\theta_{s}$ $\left(\theta_{a, 9 \mathrm{~m}}-\theta_{s}\right.$ for SHEBA $)$ and blue triangles represent $\theta_{a, 2 \mathrm{~m}}-\theta_{s}\left(\theta_{a, 3 \mathrm{~m}}-\theta_{s}\right.$ for SHEBA $)$ as functions of wind speed at $10 \mathrm{~m}$ ( $2 \mathrm{~m}$ for NP39, $9 \mathrm{~m}$ for SHEBA). Red lines show $\theta_{a, 4 \mathrm{~m}}-\theta_{s}$ as function of $U_{4 \mathrm{~m}}$ as simulated by the 1D model after 12 days of cooling (dashed line) and as given by the STDP analytical solution (solid line). The 50th-percentile curves for the observed $\Delta \theta$ are shown with black solid and dashed lines.

percentiles for data binned into the wind speed intervals of the $1 \mathrm{~m} \mathrm{~s}^{-1}$ width. Note that only the values of $\mathrm{LW}<-20 \mathrm{~W} \mathrm{~m}^{-2}$ are considered to filter out cloudy cases. Both the 10th- and 50th-percentile curves show that LW becomes more negative with increasing wind speed in the region $U<10 \mathrm{~m} \mathrm{~s}^{-1}$. In particular, LW is decreasing from about $-30 \mathrm{Wm}^{-2}$ for $U=2 \mathrm{~m} \mathrm{~s}^{-1}$ to about $-60 \mathrm{~W} \mathrm{~m}^{-2}$ for $U=10 \mathrm{~m} \mathrm{~s}^{-1}$. It is interesting that for $U>10 \mathrm{~m} \mathrm{~s}^{-1}$ the values of LW become again less negative. This might be due to the fact that very strong winds are associated with transient cyclones and the advection of warm and moist air, which leads to increased downwelling radiation.

The values of LW simulated by the 1D model are also shown in Fig. 11. The modeled dependency of LW on $U$ is very similar to the observed one. This suggests that indeed it is the dependency of the ABL height and the inversion strength on wind speed that is behind the dependency of LW on $U$. However, this dependency has to be studied in more detail.

The steady-state solutions considered in this section are attractive due to their simplicity. However, it is a question, how often such conditions are observed in nature. A study by Overland et al. (2000) provides some evidence supporting a plausibility of the steady-state assumption. There, the authors show that the negative heat flux over thick ice floes (as measured at the SHEBA camp) was almost compensated by large positive heat flux through leads and thin ice. This resulted in small close-to-zero values of the area-averaged heat flux over the $100 \mathrm{~km} \times 100 \mathrm{~km}$ region around the SHEBA camp. This implies that on the considered spatiotemporal scale the ABL in the central Arctic is nearly in a steady state or only slowly evolving. The time scale at which the steady state is reached in a cooling ABL is considered in more detail in appendix B.

\section{Conclusions}

An analytical model of the atmospheric boundary layer (ABL) coupled to a sea ice slab is presented describing the thermal regime over sea ice during clear-sky cooling in polar night. Analytical solutions reveal the sensitivity of the air and surface temperatures to 

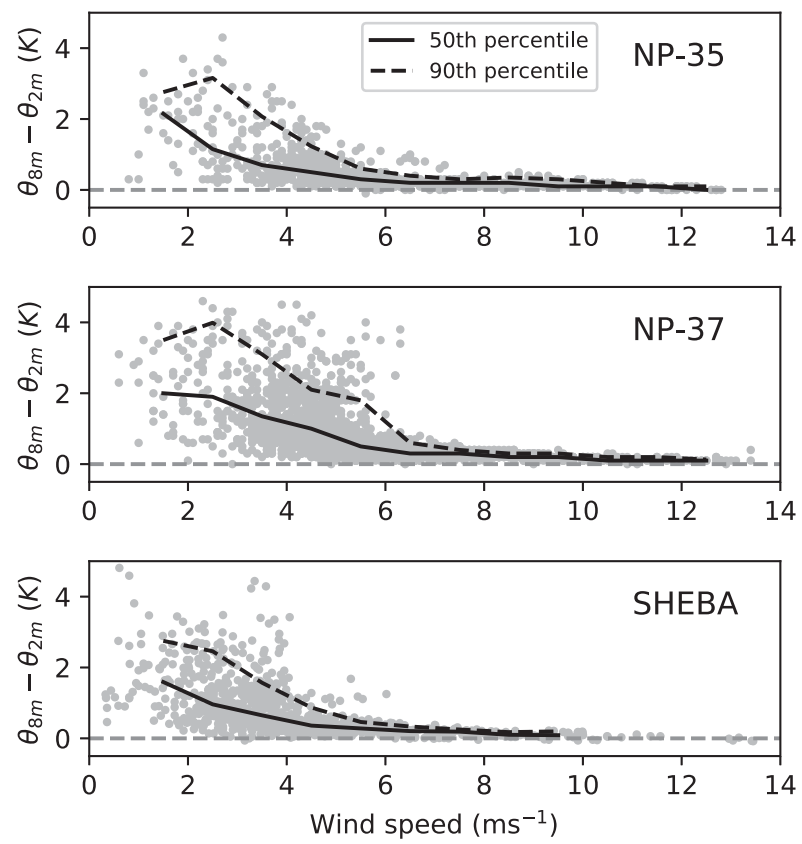

FIG. 10. The observed potential temperature difference $\theta_{8 \mathrm{~m}}-\theta_{2 \mathrm{~m}}$ at the (top) NP-35, (middle) NP-37, and (bottom) SHEBA stations as function of wind speed at $10-\mathrm{m}$ height.

external parameters such as the depths and conductivities of the snow and ice layers, surface roughness, wind speed, and sea ice concentration. Particularly, the latter two are the focus of this study and are shown to have a strong impact on both the air and snow-surface temperatures and on the stability over sea ice.

The presented theoretical model highlights several important features of contrasting ABL regimes that are governed by wind speed and are amplified by the presence of leads. First of all, the model describes the transition from a weakly stable (coupled) regime to a strongly stable (decoupled) regime when wind speed is decreasing. In this respect the model is similar to the conceptual model presented earlier by Van de Wiel et al. (2017), but contains several important developments described in section 1. Most importantly, the model takes into account leads. The analytical solutions demonstrate that the presence of leads increases stability over sea ice and promotes further decoupling. Thus, a decrease of the sea ice concentration leads to an increase of the threshold value of wind speed at which the transition occurs and also to an increase of the airice temperature difference.

One of the consequences of decoupling is the nonmonotonic dependency of the air temperature on wind speed, which is produced by the theoretical model. Namely, the coldest temperatures occur for the threshold value of wind speed. In the coupled regime, air temperature is increasing with wind speed. The theoretical model highlights several mechanisms leading to such a dependency. First, the turbulent heat flux from leads is increasing with wind speed and warms the ABL. Second, the cooling time scale is also increasing with wind speed in the coupled regime even in the absence of leads.

In the decoupled regime, the cooling time scale is increasing with decreasing wind speed. Also, the positive heat flux from leads is not any more effectively balanced by the negative heat flux over sea ice. The latter is suppressed by stratification. This results in increase of air temperature when wind speed is decreasing below the threshold value.

To summarize, the theoretical model reveals the following effects of the presence of leads: 1) a strong ABL warming, 2) an increase of stability over sea ice and an amplification of decoupling, and 3) an impact on the cooling time scale of the ABL.

The theoretical model results are evaluated by comparison with results of a single-column numerical ABLsea ice model. The results of the two models are in a very good qualitative and even quantitative agreement. The 1D model mimics to some extent the behavior of a single column of a coarse resolution atmospheric model. Thus, one can expect that the described effects of wind speed and sea ice concentration are also present in climate simulations and in the numerical weather predictions, as well as in the atmospheric reanalyses. The increase of stratification and decoupling might play an important role, especially for the simulations of the sea ice drift, leading to the reduction of the atmospheric drag coefficient over sea ice.

Observational support for our conclusions is provided by data from four drifting stations: the Russian North Pole-35, -37, and -39 stations and the SHEBA station. The coldest temperatures observed during the polar night period at all stations demonstrate a pronounced dependency on wind speed, which is in good agreement with the theoretical model result. This concerns primarily the increase of temperature with wind speed. Moreover, at all the stations the minimal temperatures are observed not for zero wind, but for a wind speed in the range of $2-4 \mathrm{~m} \mathrm{~s}^{-1}$, also in agreement with the theoretical prediction.

A wind-driven transition to the strongly stable regime is observed at three out of four stations. The largest airice temperature differences were observed at low wind speed at the NP-37 station and reach up to $10 \mathrm{~K}$ (for air temperature measured at $8-\mathrm{m}$ height). It is intriguing that at NP-39 there is no evidence of decoupling at low wind speed. This phenomenon needs further investigation. 


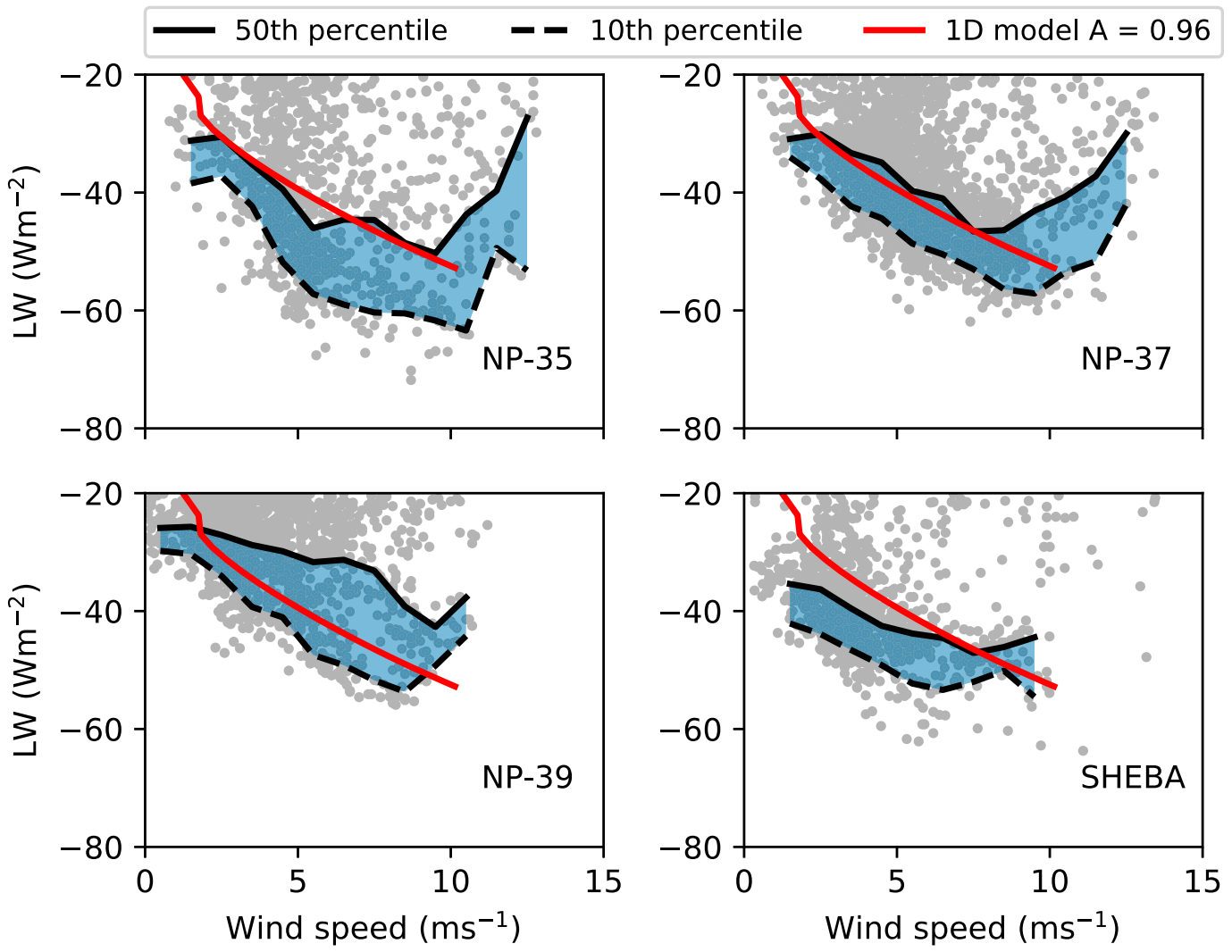

FIG. 11. The observed net longwave radiative flux (LW) at the (top left) NP-35, (top right) NP-37, (bottom left) NP-39, and (bottom right) SHEBA stations as a function of wind speed at $10 \mathrm{~m}$ ( $2 \mathrm{~m}$ for NP-39 and $9 \mathrm{~m}$ for SHEBA). The area between the 10th- and 50th-percentile curves is shaded with blue. The red curve represents the 1D model solution for $A=0.96$.

An important result of our study is also the sensitivity of the net longwave radiative flux $(\mathrm{LW})$ at the surface to wind speed, which is obtained in the $1 \mathrm{D}$ model and found also in the observations. In particular, LW becomes more negative when wind speed is increased. The $1 \mathrm{D}$ solutions suggest that this is related to the dependency of two parameters on wind speed. These are the strength of the inversion capping the $\mathrm{ABL}$ and the $\mathrm{ABL}$ height. The dependency of LW on wind speed serves as a negative feedback allowing the ABL neither to cool too much at low wind speed nor to become warmer when wind speed is increasing.

It is worth to note that several processes that potentially have an important impact on the thermal regime over sea ice were neglected in this study. These are the horizontal advection of heat and subsidence. The latter was shown to play an important role in the formation of strong inversions over the Antarctic Plateau (Baas et al. 2018; Vignon et al. 2018) and might as well be important in the Artic.

We believe that the presented dependencies of the thermodynamic state of the coupled ABL-sea ice system on wind speed can be used for the diagnostics of the climate and weather prediction models. Such models often poorly resolve the stable ABL due to the use of a coarse grid. Thus, additional diagnostics that can reveal their drawbacks might be very valuable. It can also help to better understand the spread in the model representation of the high-latitude warming (e.g., Bintanja et al. 2012).

Acknowledgments. The authors thank the four anonymous reviewers for their helpful comments and also the overwintering crew at the Russian North Pole stations and at the SHEBA ice camp for their hard work to obtain the observations. D.G.C. worked on the analytical and numerical modelling presented in this paper. His numerical modeling and the work of C.L. is funded by the Deutsche Forschungsgemeinschaft (DFG; German Research Foundation)-Project 268020496-TRR 172, within the Transregional Collaborative Research Center "Arctic Amplification: Climate Relevant Atmospheric and Surface Processes, and Feedback Mechanisms $(\mathrm{AC})^{3, "}$ and by DFG Grant LU 818/5-1. Analytical modelling by D.G.C. and the work of I.A.M. on the analysis of the observations is supported by the Russian 
Science Foundation Grant 18-77-10072. The work of A.P.M. is supported by the Russian Ministry of Education and Science Grant RFMEFI61617X0076.

\section{APPENDIX A}

\section{Sensitivity to Model Parameters}

Analytical solution (25) depends on the effective thermal conductance $\lambda_{C}$ of the snow-ice slab given by (16). In particular, $\lambda_{C}$ depends on the ratios $k_{s} / h_{s}$ and $k_{i} / h_{i}$. This is the way that the variations of the snow and ice depths $h_{s, i}$ and their thermal conductivities $k_{s, i}$ affect the solution.

According to the review of Makshtas (1998), $k_{s}$ and $k_{i}$ depend on many various factors and are highly variable in nature. Also, the depths of the snow and ice layers vary a lot. Let us assume the following ranges of variability for these parameters: $0.1-0.4 \mathrm{~W} \mathrm{~m}^{-1} \mathrm{~K}^{-1}$ for $k_{s}$, $1.5-2.5 \mathrm{~m}^{-1} \mathrm{~K}^{-1}$ for $k_{i}, 0.05-1 \mathrm{~m}$ for $h_{s}$, and $1-3 \mathrm{~m}$ for $h_{i}$. The corresponding range for $\lambda_{C}$ is $0.1-1.5 \mathrm{~W} \mathrm{~m}^{-2} \mathrm{~K}^{-1}$.

As expected, the analytical solution for $\theta_{a}$ demonstrates a large sensitivity to the value of $\lambda_{C}$, as shown in the top panels of Fig. A1. Thinner snow and ice layers (or more conductive) corresponding to larger values of $\lambda_{C}$ result in a larger air temperature. An increase of $\lambda_{C}$ leads also to a decrease of $\Delta \theta$ in a weak-wind regime. Apart from this, the dependency of $\theta_{a}$ and $\Delta \theta$ on wind speed and on the sea ice concentration remains qualitatively the same within the considered range of $\lambda_{C}$.

The solution also depends on the surface roughness lengths for momentum $z_{0 m}$ and heat $z_{0 t}$. Based on SHEBA observations Andreas et al. (2010) showed a large variation of $z_{0 m}$ and $z_{0 t} / z_{0 m}$ over sea ice over a range spanning several orders of magnitude. Based on their Figs. 1 and 5, we vary $z_{0 m}$ in the range from $10^{-4}$ to $10^{-1} \mathrm{~m}$, and $z_{0 t} / z_{0 m}$ in the range from $10^{-2}$ to 10 . Figure A1 (middle and bottom panels) shows that the increase of the roughness length and of the ratio $z_{0 t} / z_{0 m}$ results in a decrease of $\Delta \theta$ and of the wind speed of transition between the strongly and weakly stable regimes. This agrees with the sensitivity of the transition wind speed to the roughness length obtained in previous studies (Shi et al. 2005; Van de Wiel et al. 2012, 2017).

\section{APPENDIX B}

\section{Cooling Time Scale in the Strong-Wind Regime}

Let us consider a model where the steady-state assumption is not used in the ABL. In the ice and snow volume, the temperature is assumed to be in equilibrium with the ABL forcing at any given time step. Thus no prognostic equations are used for the snow and ice temperatures. The thickness of snow and ice layers as well as all other snow and ice parameters such as densities and heat conductivities are assumed constant.

We switch from the surface-layer temperature $\theta_{a}$ and wind speed $U$ to $\theta_{m}$ and $U_{m}$, which represent averages over the ABL depth. Such transition to the mixed-layer variables is inevitable and follows from the procedure of the vertical averaging. Equations describing the evolution of $\theta_{m}$ are

$$
\begin{gathered}
\frac{d \theta_{m}}{d t}=\frac{U_{m}}{h_{a}}\left[A C_{H, s}\left(\theta_{s}-\theta_{m}\right)+(1-A) C_{H, w}\left(\theta_{\text {lead }}-\theta_{m}\right)\right] \\
\mathrm{LW}+\frac{k_{s}}{h_{s}}\left(\theta_{i}-\theta_{s}\right)=\rho_{a} c_{p} C_{H, s} U_{m}\left(\theta_{s}-\theta_{m}\right) \\
0=-\frac{k_{i}}{h_{i}}\left(\theta_{i}-\theta_{w}\right)+\frac{k_{s}}{h_{s}}\left(\theta_{s}-\theta_{i}\right)
\end{gathered}
$$

where $h_{a}$ is the ABL height and the longwave radiative balance (LW) is given by (10). Note that $U_{m}$ and $h_{a}$ remain now in (B1), while they are absent in its steadystate counterpart, (1).

In the system (B1)-(B3) we neglect entrainment and assume that $h_{a}$ is independent of time, as we are interested in longer time scales when the ABL growth becomes rather small. According to the $1 \mathrm{D}$ model results (not shown here) $h_{a}$ reaches its quasi-steady value within the first several hours of cooling, which is in agreement with earlier studies (Cuxart et al. 2006). This is about an order of magnitude faster compared to the ABL cooling time scale (several tens of hours). In fact, $h_{a}$ continues to grow very slowly throughout the whole duration of the 1D model simulation, but this growth rate is much smaller compared to the initial ABL growth. Based on that, we neglect the variation of $h_{a}$ and its parameterization as function of $U_{m}$ is introduced further.

The ABL height is diagnosed from the 1D model results as the height at which the momentum flux is equal to $5 \%$ of its surface value. Figure B1 shows $h_{a}$ as function of $U_{m}$. The figure suggests that the dependency of $h_{a}$ on $U_{m}$ (and also on $u_{\star}$, not shown here) is close to linear in the $1 \mathrm{D}$ model and is well approximated by

$$
h_{a}=b U_{m},
$$

where $b=20 \mathrm{~s}, h_{a}$ is given in meters, and $U_{m}$ is in meters per second. This parameterization is of the same level of simplicity as, for example, $h_{a}=60 u_{10}$ proposed 

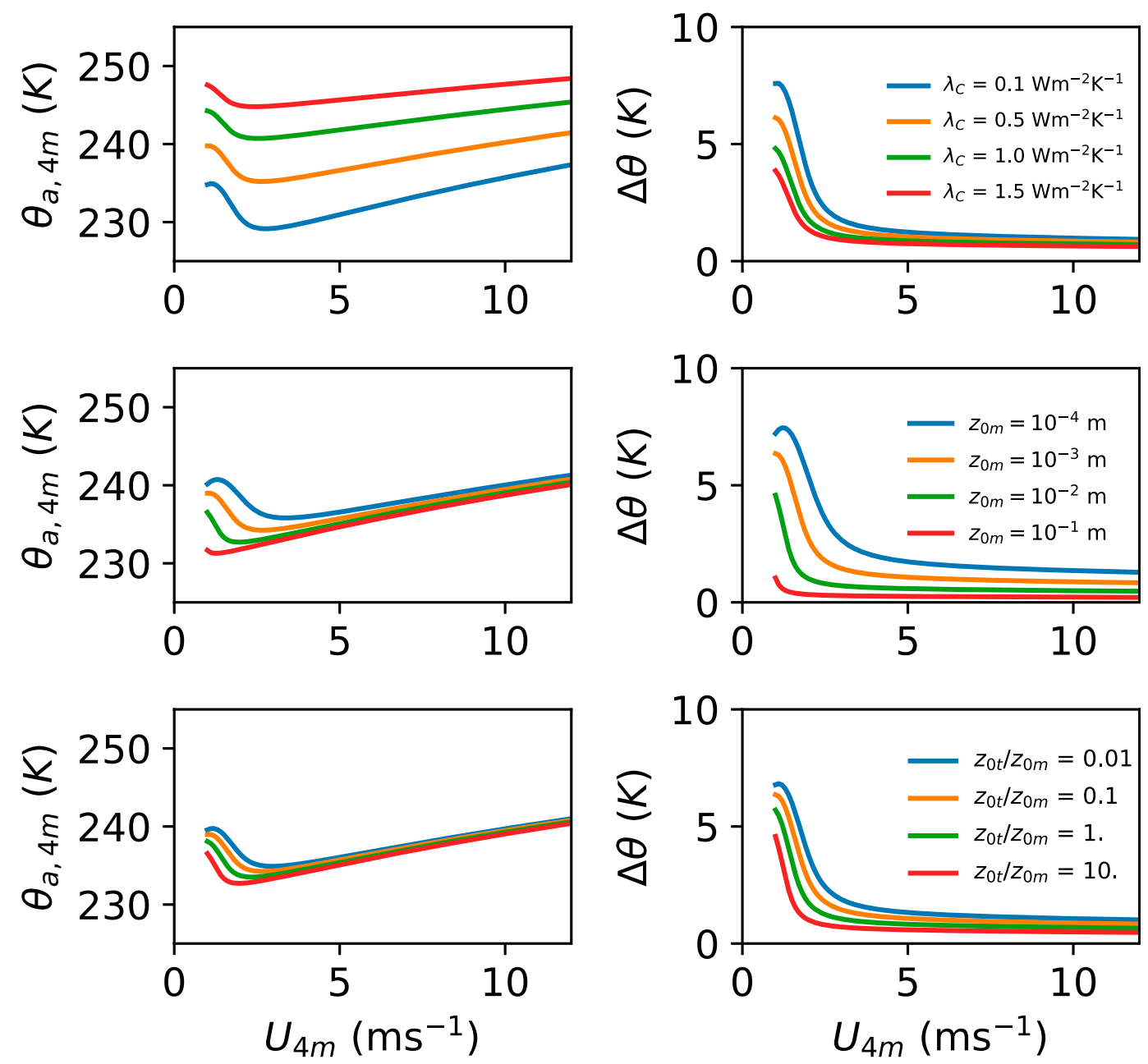

FIG. A1. Sensitivity of the analytical solution for $\theta_{a}$ and $\Delta \theta=\theta_{a}-\theta_{s}$ to the parameters: (top) the snow-ice bulk thermal conductance $\lambda_{C}$, (middle) roughness length $z_{0 m}$, and (bottom) $z_{0 t} / z_{0 m}$. All curves are obtained for the sea ice concentration $A=0.96$.

by Koracin and Berkowicz (1988) or $h_{a}=700 u_{\star}$ by Steeneveld et al. (2007), which are both based on observations, including those in high latitudes.

The exchange coefficient $C_{H}$ has to be defined using the ABL similarity theory (e.g., Arya 1977) because the ABL-averaged $\theta_{m}$ and $U_{m}$ are used in (B1). This results in smaller values for $C_{H, s}$. We are now interested in the strong-wind regime where the stability effect on $C_{H, s}$ is small. Thus, we set $C_{H, s}$ and $C_{H, w}$ to a constant value of $0.8 \times 10^{-3}$.

To obtain the analytical solution it is convenient to introduce new variables $\overline{\theta_{m}}=\theta_{m}-\theta_{m, \infty}, \overline{\theta_{s}}=\theta_{s}-\theta_{s, \infty}$, and $\overline{\theta_{i}}=\theta_{i}-\theta_{i, \infty}$, where $\theta_{x, \infty}$ are the steady-state values of the corresponding temperatures for $t \rightarrow \infty$. Using the new variables we rewrite the system (B1)-(B3) as

$$
\tau_{a} \frac{d \overline{\theta_{m}}}{d t}=Y \overline{\theta_{s}}-\overline{\theta_{m}}
$$

$$
\overline{\theta_{s}}=X \overline{\theta_{m}},
$$

where

$$
\begin{gathered}
\tau_{a}=\frac{h_{a}}{U_{m}\left[A C_{H, s}+(1-A) C_{H, w}\right]}, \\
Y=\frac{A C_{H, s}}{A C_{H, s}+(1-A) C_{H, w}}, \\
X=\frac{\lambda_{T s}+\lambda_{\mathrm{Ra}}}{\lambda_{T s}+\lambda_{\mathrm{Ra}}+\lambda_{\mathrm{Ri}}+\lambda_{C}} .
\end{gathered}
$$

In (B9) $\lambda$ represents the heat conductance of the corresponding part of the system denoted by the lower index. The ABL cooling time scale $\tau_{a}$ given by (B7) represents the $e$-folding cooling time for fixed $\theta_{s}$ being smaller than the initial $\theta_{m}$. 


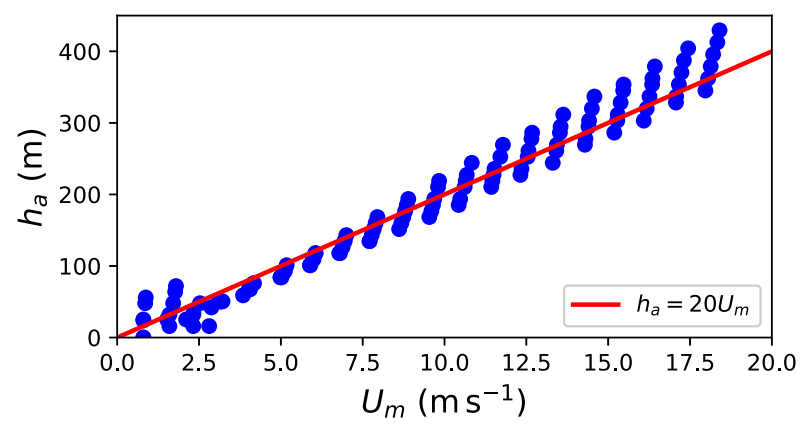

FIG. B1. Boundary layer height as a function of the ABLaveraged wind speed $U_{m}$ as simulated by the $1 \mathrm{D}$ model after 6 days of cooling. Red line represents the formula $h_{a}=20 U_{m}$.

Equations (B5) and (B6) are combined into

$$
\tau \frac{d \overline{\theta_{m}}}{d t}=-\overline{\theta_{m}}
$$

where $\tau$ is the cooling time scale of the coupled ABL-sea ice system and is given by

$$
\tau=\frac{\tau_{a}}{1-Y X} .
$$

The solution of (B10) is that of an exponential decay given by

$$
\overline{\theta_{m}}=\overline{\theta_{0}} \exp \left(-\frac{t}{\tau}\right)
$$

where $\overline{\theta_{0}}$ is the initial value of $\overline{\theta_{m}}=\theta_{m, 0}-\theta_{m, \infty}$, and $\theta_{m, \infty}$ is the steady-state value that is known from (18).

The solution reflects several mechanisms through which $U_{m}$ is influencing the cooling time scale $\tau$. First, we notice from (B7) that the ABL cooling time scale $\tau_{a}$ is proportional to $h_{a} / U_{m}$. This ratio shows that, on one hand, $\tau_{a}$ is decreasing when $U_{m}$ is increasing. The reason is that the atmospheric turbulent heat flux to sea ice increases with $U_{m}$. This makes the ABL cool faster. On the other hand, larger $U_{m}$ results in larger ABL height $h_{a}$ and, consequently, larger $\tau_{a}$. The resulting effect of $U_{m}$ on $\tau_{a}$ depends on the exact functional form of the dependency of $h_{a}$ upon $U_{m}$ (e.g., Zilitinkevich and Baklanov 2002; Vickers and Mahrt 2004; Steeneveld et al. 2007). In our $1 \mathrm{D}$ simulations the ratio $h_{a} / U_{m}$ is approximately constant.

According to (B11), $U_{m}$ is also present in $\lambda_{T s}=\rho c_{p} U C_{H, s}$. The latter represents the strength of the turbulent
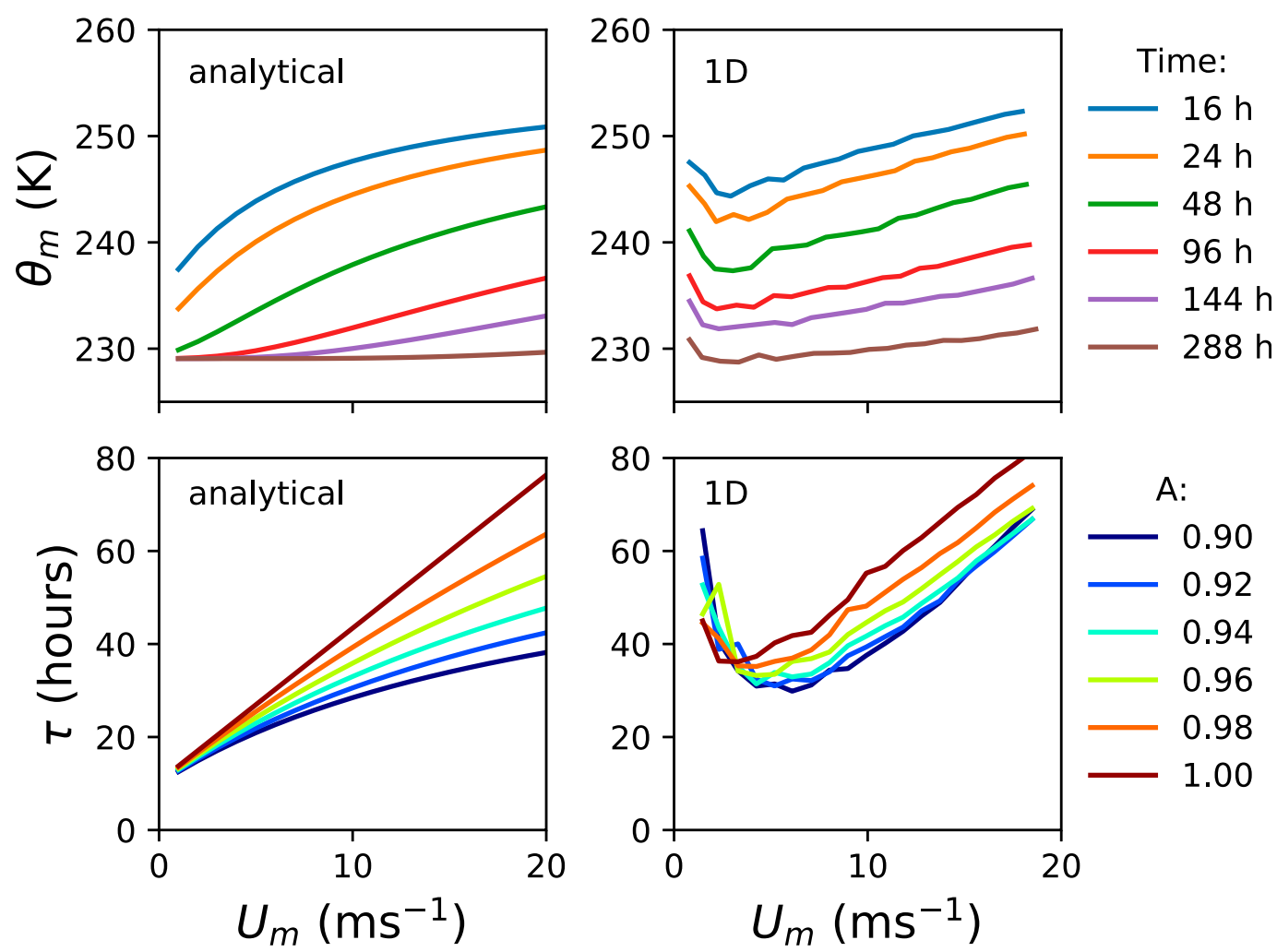

FIG. B2. (top) Potential temperature averaged over the ABL height as a function of wind speed and time for $A=1$ and (bottom) the cooling time scale $\tau$ as a function of $A$ and $U_{m}$ based on (left) the theoretical model solutions for constant $C_{H, s}$ and (right) the $1 \mathrm{D}$ model results. 
coupling between $\theta_{m}$ and $\theta_{s}$. Namely, (B11) shows that $\tau$ is increasing when $U_{m}$ is increasing. Since $h_{a} / U_{m}$ is constant in our simulations, it is the effect of $U_{m}$ on $\lambda_{T s}$ that is responsible for the dependency of the cooling time scale, and, consequently, of $\theta_{m}$, on $U_{m}$.

The upper panels of Fig. B2 show the time evolution of $\theta_{m}$ based on results of the analytical and 1D modeling for $A=1$. First of all, it is obvious that even without leads a nonmonotonic dependency of $\theta_{m}$ on $U_{m}$ is found in the nonstationary solutions of the $1 \mathrm{D}$ model. The analytical solution for constant $C_{H, s}$ shows a monotonic increase of $\theta_{m}$ with $U_{m}$, which is in agreement with the 1D model results in the strong wind regime.

Figure B2 shows the dependency of the cooling time scale $\tau$ on wind speed and the sea ice concentration $A$. In the $1 \mathrm{D}$ model results, the cooling time scale is found as the time when $\theta_{m}-\theta_{m, 12 \text { days }}$ becomes $e$ times smaller than its initial value.

It is clear that $\tau$ has a nonmonotonic dependency on $U_{m}$ in the $1 \mathrm{D}$ simulations. In particular, the fastest cooling occurs for $U_{m}$ in the range of $4-8 \mathrm{~m} \mathrm{~s}^{-1}$. The latter value depends on $A$. When $A$ is decreasing, the wind speed $U_{m}$ for which the fastest cooling is obtained is increasing. In general, smaller $A$ (larger lead area fraction) results in a faster cooling. In the analytical solution for the constant $C_{H, s}$, the dependency of $\tau$ on $U_{m}$ is monotonic. As expected, the increase of $\tau$ at low wind speed is not reproduced by the analytical solution, because it does not take into account the effect of stability on $C_{H, s}$.

\section{REFERENCES}

Andreas, E. L., and B. A. Cash, 1999: Convective heat transfer over wintertime leads and polynyas. J. Geophys. Res., 104, $25721-$ 25 734, https://doi.org/10.1029/1999JC900241.

— , P. S. Guest, P. O. G. Persson, C. W. Fairall, T. W. Horst, R. E. Moritz, and S. R. Semmer, 2002: Near-surface water vapor over polar sea ice is always near ice saturation. J. Geophys. Res., 107, 8033, https://doi.org/10.1029/2000JC000411.

— , P. O. G. Persson, A. A. Grachev, R. E. Jordan, T. W. Horst, P. S. Guest, and C. W. Fairall, 2010: Parameterizing turbulent exchange over sea ice in winter. J. Hydrometeor., 11, 87-104, https://doi.org/10.1175/2009JHM1102.1.

Arya, S. P. S., 1977: Suggested revisions to certain boundary layer parameterization schemes used in atmospheric circulation models. Mon. Wea. Rev., 105, 215-227, https://doi.org/10.1175/ 1520-0493(1977)105<0215:SRTCBL $>2.0 . C O ; 2$.

Baas, P., B. J. H. van de Wiel, E. van Meijgaard, E. Vignon, C. Genthon, S. J. A. van der Linden, and S. R. de Roode, 2018: Transitions in the wintertime near-surface temperature inversion at Dome C, Antarctica. Quart. J. Roy. Meteor. Soc. 145, 930-946. https://doi.org/10.1002/qj.3450.

Beljaars, A. C. M., and A. A. M. Holtslag, 1991: Flux parameterization over land surfaces for atmospheric models. J. Appl. Meteor., 30, 327-341, https://doi.org/10.1175/1520-0450(1991) $030<0327$ :FPOLSF $>2.0 . \mathrm{CO} ; 2$.
Bintanja, R., E. C. van der Linden, and W. Hazeleger, 2012: Boundary layer stability and Arctic climate change: A feedback study using EC-Earth. Climate Dyn., 39, 2659-2673, https://doi.org/10.1007/s00382-011-1272-1.

Blackadar, A. K., 1962: The vertical distribution of wind and turbulent exchange in a neutral atmosphere. J. Geophys. Res., 67, 3095-3102, https://doi.org/10.1029/JZ067i008p03095.

Cassano, J. J., M. A. Nigro, and M. A. Lazzara, 2016: Characteristics of the near-surface atmosphere over the Ross Ice Shelf, Antarctica. J. Geophys. Res. Atmos., 121, 3339-3362, https:// doi.org/10.1002/2015JD024383.

Castellani, G., C. Lüpkes, S. Hendricks, and R. Gerdes, 2014: Variability of Arctic sea-ice topography and its impact on the atmospheric surface drag. J. Geophys. Res., 119, 6743-6762, https://doi.org/10.1002/2013JC009712.

Chechin, D. G., C. Lüpkes, I. A. Repina, and V. M. Gryanik, 2013: Idealized dry quasi 2-D mesoscale simulations of cold-air outbreaks over the marginal sea ice zone with fine and coarse resolution. J. Geophys. Res. Atmos., 118, 8787-8813, https:// doi.org/10.1002/jgrd.50679.

Chou, M.-D., M. J. Suarez, X.-J. Liang, and M.-H. Yan, 2001: A thermal infrared radiation parameterization for atmospheric studies. NASA/TM-2001-104606, Vol. 19, 54 pp., https:// ntrs.nasa.gov/archive/nasa/casi.ntrs.nasa.gov/20010072848.pdf.

Cuxart, J., and Coauthors, 2006: Single-column model intercomparison for a stably stratified atmospheric boundary layer. Bound.-Layer Meteor., 118, 273-303, https://doi.org/10.1007/ s10546-005-3780-1.

Delage, Y., 1974: A numerical study of the nocturnal atmospheric boundary layer. Quart. J. Roy. Meteor. Soc., 100, 351-364, https://doi.org/10.1002/qj.49710042507.

Derbyshire, S. H., 1999: Stable boundary-layer modelling: Established approaches and beyond. Bound.-Layer Meteor., 90, 423-446, https://doi.org/10.1023/A:1001749007836.

Grachev, A. A., E. L Andreas, C. W. Fairall, P. S. Guest, and P. O. G. Persson, 2007: SHEBA flux-profile relationships in the stable atmospheric boundary layer. Bound.-Layer Meteor., 124, 315-333, https://doi.org/10.1007/s10546-007-9177-6.

Gryanik, V. M., and C. Lüpkes, 2018: An efficient non-iterative bulk parametrization of surface fluxes for stable atmospheric conditions over polar sea-ice. Bound.-Layer Meteor., 166, 301325, https://doi.org/10.1007/s10546-017-0302-x.

Holtslag, A. A. M., G. J. Steeneveld, and B. J. H. van de Wiel, 2007: Role of land-surface temperature feedback on model performance for the stable boundary layer. Bound.-Layer Meteor., 125, 361-376, https://doi.org/10.1007/s10546-0079214-5.

Hudson, S. R., and R. E. Brandt, 2005: A look at the surface-based temperature inversion on the Antarctic Plateau. J. Climate, 18, 1673-1696, https://doi.org/10.1175/JCLI3360.1.

Kaleschke, L., C. Lüpkes, T. Vihma, J. Haarpaintner, A. Bochert, J. Hartmann, and G. Heygster, 2001: SSM/I sea ice remote sensing for mesoscale ocean-atmosphere interaction analysis. Can. J. Remote Sens., 27, 526-537, https://doi.org/ 10.1080/07038992.2001.10854892.

König-Langlo, G., and E. Augstein, 1994: Parameterization of the downward long-wave radiation at the Earth's surface in polar regions. Meteor. Z., 3, 343-347, https://doi.org/10.1127/metz/3/ 1994/343.

Koracin, D., and R. Berkowicz, 1988: Nocturnal boundary-layer height: Observations by acoustic sounders and predictions in terms of surface-layer parameters. Bound.-Layer Meteor., 43, 65-83, https://doi.org/10.1007/BF00153969. 
Louis, J.-F., M. Tiedtke, and J.-F. Geleyn, 1982: A short history of the PBL parameterization at ECMWF. Workshop on Planetary Boundary Layer Parameterization, Reading, United Kingdom, ECMWF, 59-79, https://www.ecmwf.int/node/10845.

Lüpkes, C., V. M. Gryanik, B. Witha, M. Gryschka, S. Raasch, and T. Gollnik, 2008a: Modeling convection over arctic leads with LES and a non-eddy-resolving microscale model. J. Geophys. Res., 113, C09028, https://doi.org/10.1029/2007JC004099.

— - T. Vihma, G. Birnbaum, and U. Wacker, 2008b: Influence of leads in sea ice on the temperature of the atmospheric boundary layer during polar night. Geophys. Res. Lett., 35, L03805, https://doi.org/10.1029/2007GL032461.

Makhotina, I. A., A. P. Makshtas, and D. G. Chechin, 2019: Meteorological winter conditions in the Central Arctic according to the drifting stations "North Pole 35-40." IOP Conf. Ser.: Earth Environ. Sci., 231, 012031, https://doi.org/10.1088/17551315/231/1/012031.

Makshtas, A. P., 1998: Thermodynamics of sea ice. Physics of IceCovered Seas, M. Leppäranta, Ed., Helsinki University Printing House, 289-304.

— V. F. Timachev, V. T. Sokolov, K. V. Yu, and I. A. Govorina, 2014: Turbulent energy exchange processes at the sea iceatmosphere interface based on historical data and data from the drifting stations "North Pole-35" and "North Pole-39." Arct. Antarct. Res., 99 (1), 53-64.

- I. A. Makhotina, and V. F. Timachev, 2019: Characteristics of atmosphere - sea ice energy exchange in the Central Arctic. IOP Conf. Ser.: Earth Environ. Sci., 231, 012034, https:// doi.org/10.1088/1755-1315/231/1/012034.

Malhi, Y. S., 1995: The significance of the dual solutions for heat fluxes measured by the temperature fluctuation method in stable conditions. Bound.-Layer Meteor., 74, 389-396, https:// doi.org/10.1007/BF00712379.

McNider, R. T., D. E. England, M. J. Friedman, and X. Shi, 1995: Predictability of the stable atmospheric boundary layer. J. Atmos. Sci., 52, 1602-1614, https://doi.org/10.1175/15200469(1995)052<1602:POTSAB > 2.0.CO;2.

— , and Coauthors, 2012: Response and sensitivity of the nocturnal boundary layer over land to added longwave radiative forcing. J. Geophys. Res., 117, D14106, https://doi.org/10.1029/ 2012JD017578.

Miranda, P. M. A., and I. N. James, 1992: Non-linear threedimensional effects on gravity-wave drag: Splitting flow and breaking waves. Quart. J. Roy. Meteor. Soc., 118, 1057-1081, https://doi.org/10.1002/qj.49711850803.

Niemelä, S., P. Räisänen, and H. Savijärvi, 2001: Comparison of surface radiative flux parameterizations: Part I: Longwave radiation. Atmos. Res., 58, 1-18, https://doi.org/10.1016/S01698095(01)00084-9.

Overland, J. E., and P. S. Guest, 1991: The Arctic snow and air temperature budget over sea ice during winter. J. Geophys. Res., 96, 4651-4662, https://doi.org/10.1029/90JC02264.

, S. L. McNutt, J. Groves, S. Salo, E. L. Andreas, and P. O. G. Persson, 2000: Regional sensible and radiative heat flux estimates for the winter Arctic during the Surface Heat Budget of the Arctic Ocean (SHEBA) experiment. J. Geophys. Res., 105, 14 093-14 102, https://doi.org/10.1029/ 1999JC000010.

Persson, P. O. G., C. W. Fairall, E. L. Andreas, P. S. Guest, and D. K. Perovich, 2002: Measurements near the Atmospheric Surface Flux Group tower at SHEBA: Near-surface conditions and surface energy budget. J. Geophys. Res., 107, 8045, https://doi.org/10.1029/2000JC000705.
Petty, A. A., M. C. Tsamados, and N. T. Kurtz, 2017: Atmospheric form drag coefficients over Arctic sea ice using remotely sensed ice topography data, spring 2009-2015. J. Geophys. Res. Earth Surf., 122, 1472-1490, https://doi.org/10.1002/2017JF004209.

Pinto, J. O., and J. A. Curry, 1995: Atmospheric convective plumes emanating from leads: 2. Microphysical and radiative processes. J. Geophys. Res., 100, 4633-4642, https://doi.org/10.1029/ 94JC02655.

Pithan, F., and Coauthors, 2016: Select strengths and biases of models in representing the Arctic winter boundary layer over sea ice: The Larcform 1 single column model intercomparison. J. Adv. Model. Earth Syst., 8, 1345-1357, https://doi.org/ 10.1002/2016MS000630.

Savijärvi, H., 2009: Stable boundary layer: Parametrizations for local and larger scales. Quart. J. Roy. Meteor. Soc., 135, 914921, https://doi.org/10.1002/qj.423.

_ 2014: High-resolution simulations of the night-time stable boundary layer over snow. Quart. J. Roy. Meteor. Soc., 140, 1121-1128, https://doi.org/10.1002/qj.2187.

Shi, X., R. T. McNider, M. P. Singh, D. E. England, M. J. Friedman, W. M. Lapenta, and W. B. Norris, 2005: On the behavior of the stable boundary layer and the role of initial conditions. Pure Appl. Geophys., 162, 1811-1829, https://doi.org/ 10.1007/s00024-005-2694-7.

Sorbjan, Z., 2014: Modelling of the evolving stable boundary layer. Bound.-Layer Meteor., 151, 407-428, https://doi.org/10.1007/ s10546-013-9893-z.

Steeneveld, G. J., B. J. H. van de Wiel, and A. A. M. Holtslag, 2007: Diagnostic equations for the stable boundary layer height: Evaluation and dimensional analysis. J. Appl. Meteor. Climatol., 46, 212-225, https://doi.org/10.1175/JAM2454.1.

Sterk, H. A. M., G. J. Steeneveld, and A. A. M. Holtslag, 2013: The role of snow-surface coupling, radiation, and turbulent mixing in modeling a stable boundary layer over Arctic sea ice. J. Geophys. Res. Atmos., 118, 1199-1217, https://doi.org/ 10.1002/jgrd.50158.

Stramler, K., A. D. Del Genio, and W. B. Rossow, 2011: Synoptically driven Arctic winter states. J. Climate, 24, 1747-1762, https://doi.org/10.1175/2010JCLI3817.1.

Sun, J., L. Mahrt, R. M. Banta, and Y. L. Pichugina, 2012: Turbulence regimes and turbulence intermittency in the stable boundary layer during CASES-99. J. Atmos. Sci., 69, 338-351, https://doi.org/10.1175/JAS-D-11-082.1.

Tetzlaff, A., L. Kaleschke, C. Lüpkes, F. Ament, and T. Vihma, 2013: The impact of heterogeneous surface temperatures on the 2-m air temperature over the Arctic ocean under clear skies in spring. Cryosphere, 7, 153-166, https://doi.org/10.5194/ tc-7-153-2013.

_ C. C. Lüpkes, and J. Hartmann, 2015: Aircraft-based observations of atmospheric boundary-layer modification over Arctic leads. Quart. J. Roy. Meteor. Soc., 141, 2839-2856, https://doi.org/ 10.1002/qj.2568.

Therry, G., and P. Lacarrère, 1983: Improving the eddy kinetic energy model for planetary boundary layer description. Bound.-Layer Meteor., 25, 63-88, https://doi.org/10.1007/ BF00122098.

Van de Wiel, B. J. H., R. J. Ronda, A. F. Moene, H. A. R. De Bruin, and A. A. M. Holtslag, 2002: Intermittent turbulence and oscillations in the stable boundary layer over land. Part I: A bulk model. J. Atmos. Sci., 59, 942-958, https://doi.org/10.1175/ 1520-0469(2002)059<0942:ITAOIT>2.0.CO;2.

, A. F. Moene, W. H. De Ronde, and H. J. J. Jonker, 2008: Local similarity in the stable boundary layer and mixing-length 
approaches: Consistency of concepts. Bound.-Layer Meteor., 128, 103-116, https://doi.org/10.1007/s10546-008-9277-y. , S. Basu, A. F. Moene, H. J. J. Jonker, G.-J. Steeneveld, and A. A. M. Holtslag, 2011: Comments on "An extremum solution of the Monin-Obukhov similarity equations." J. Atmos. Sci., 68, 1405-1408, https://doi.org/10.1175/2010JAS3680.1.

— , A. F. Moene, H. J. J. Jonker, P. Baas, S. Basu, J. M. M. Donda, J. Sun, and A. A. M. Holtslag, 2012: The minimum wind speed for sustainable turbulence in the nocturnal boundary layer. J. Atmos. Sci., 69, 3116-3127, https://doi.org/ 10.1175/JAS-D-12-0107.1.

—, and Coauthors, 2017: Regime transitions in near-surface temperature inversions: A conceptual model. J. Atmos. Sci., 74, 1057-1073, https://doi.org/10.1175/JAS-D-16-0180.1.

van Ulden, A. P., and A. A. M. Holtslag, 1985: Estimation of atmospheric boundary layer parameters for diffusion applications. J. Climate Appl. Meteor., 24, 1196-1207, https://doi.org/ 10.1175/1520-0450(1985)024<1196:EOABLP > 2.0.CO;2.

Vickers, D., and L. Mahrt, 2004: Evaluating formulations of stable boundary layer height. J. Appl. Meteor., 43, 1736-1749, https:// doi.org/10.1175/JAM2160.1.

Vignon, E., and Coauthors, 2017: Stable boundary-layer regimes at Dome C, Antarctica: Observation and analysis. Quart. J. Roy. Meteor. Soc., 143, 1241-1253, https://doi.org/10.1002/qj.2998.

- - F. Hourdin, C. Genthon, B. J. H. Van de Wiel, H. Gallée, J.-B. Madeleine, and J. Beaumet, 2018: Modeling the dynamics of the atmospheric boundary layer over the
Antarctic Plateau with a general circulation model. J. Adv. Model. Earth Syst., 10, 98-125, https://doi.org/ 10.1002/2017MS001184

Vihma, T., and R. Pirazzini, 2005: On the factors controlling the snow surface and 2-m air temperatures over the Arctic sea ice in winter. Bound.-Layer Meteor., 117, 73-90, https://doi.org/ 10.1007/s10546-004-5938-7.

_- J. Hartmann, and C. Lüpkes, 2003: A case study of an on-ice air flow over the Arctic marginal sea-ice zone. Bound.-Layer Meteor., 107, 189-217, https://doi.org/ 10.1023/A:1021599601948.

_ - and Coauthors, 2014: Advances in understanding and parameterization of small-scale physical processes in the marine Arctic climate system: A review. Atmos. Chem. Phys., 14, 9403-9450, https://doi.org/10.5194/acp-14-9403-2014.

Walsh, J. E., and W. L. Chapman, 1998: Arctic cloud-radiationtemperature associations in observational data and atmospheric reanalyses. J. Climate, 11, 3030-3045, https://doi.org/ 10.1175/1520-0442(1998)011<3030:ACRTAI > 2.0.CO;2.

Walters, J. T., R. T. McNider, X. Shi, W. B. Norris, and J. R. Christy, 2007: Positive surface temperature feedback in the stable nocturnal boundary layer. Geophys. Res. Lett., 34, L12709, https://doi.org/10.1029/2007GL029505.

Zilitinkevich, S., and A. Baklanov, 2002: Calculation of the height of the stable boundary layer in practical applications. Bound.-Layer Meteor., 105, 389-409, https://doi.org/ 10.1023/A:1020376832738. 